\title{
Process Simulation and Control Optimization of a Blast Furnace Using Classical Thermodynamics Combined to a Direct Search Algorithm
}

\author{
JEAN-PHILIPPE HARVEY and AÏMEN E. GHERIBI
}

\begin{abstract}
Several numerical approaches have been proposed in the literature to simulate the behavior of modern blast furnaces: finite volume methods, data-mining models, heat and mass balance models, and classical thermodynamic simulations. Despite this, there is actually no efficient method for evaluating quickly optimal operating parameters of a blast furnace as a function of the iron ore composition, which takes into account all potential chemical reactions that could occur in the system. In the current study, we propose a global simulation strategy of a blast furnace, the 5-unit process simulation. It is based on classical thermodynamic calculations coupled to a direct search algorithm to optimize process parameters. These parameters include the minimum required metallurgical coke consumption as well as the optimal blast chemical composition and the total charge that simultaneously satisfy the overall heat and mass balances of the system. Moreover, a Gibbs free energy function for metallurgical coke is parameterized in the current study and used to fine-tune the simulation of the blast furnace. Optimal operating conditions and predicted output stream properties calculated by the proposed thermodynamic simulation strategy are compared with reference data found in the literature and have proven the validity and high precision of this simulation.
\end{abstract}

DOI: $10.1007 / \mathrm{s} 11663-013-0004-9$

(C) The Minerals, Metals \& Materials Society and ASM International 2013

\section{INTRODUCTION}

IRON making is the pyrometallurgical process of turning solid iron ore materials into liquid hot metal called pig iron typically saturated with carbon $(\approx 5 \mathrm{wt}$ pct $)$. The process uses injection of air and metallurgical coke in a counter-current flow reactor called a blast furnace (BF). This is probably one of the metallurgical processes that has captivated the most attention of scientists and engineers in the past. The major chemical reactions occurring in the $\mathrm{BF}$ are (1) the combustion of metallurgical coke by hot air (potentially enriched in $\mathrm{O}_{2}$ ) at the tuyere level, resulting in the production of a CO-rich reducing gas; and (2) the direct and indirect reductions of the iron-rich minerals present in the ore by metallurgical coke and the reducing gas, respectively. The composition of the available iron ore may include impurities such as $\mathrm{SiO}_{2}, \mathrm{Al}_{2} \mathrm{O}_{3}, \mathrm{P}_{2} \mathrm{O}_{5}, \mathrm{MgO}$, $\mathrm{CaO}, \mathrm{Na}_{2} \mathrm{O}, \mathrm{K}_{2} \mathrm{O}$, and $\mathrm{S}$. Minor chemical reactions such as the reduction of these impurities can occur and affect drastically the quality of the final pig iron product, the

JEAN-PHILIPPE HARVEY, Ph.D. Postdoctoral Fellow, formerly with the Center for Research in Computational Thermochemistry, Department of Chemical Engineering, Ecole Polytechnique de Montréal, C.P. 6079, Station Downtown, Montréal, QC H3C 3A7, Canada, is now with the Geological and Earth Planetary Sciences Division, California Institute of Technology, Pasadena, CA. Contact e-mail: jpharvey@caltech.edu. AÏMEN E. GHERIBI, Ph.D. Research Fellow, is with Center for Research in Computational Thermochemistry, Department of Chemical Engineering, École Polytechnique de Montréal.

Manuscript submitted July 18, 2013.

Article published online December 12, 2013. chemical nature of emissions as well as the productivity of the BF.

From a classical thermodynamic standpoint, a BF can be viewed as a complex system in which several local equilibrium states occur, as will be shown in the current study. There are a no. of major phases experimentally observed and considered in the fundamental study of this reactor. The first is the gas phase, which originates from the combustion of metallurgical coke by air at the bottom of the reactor. This results in $\mathrm{N}_{2}$ - and $\mathrm{CO}$-rich compositions (reducing gas) producing a final exhaust gas consisting mainly of $\mathrm{N}_{2}, \mathrm{CO}, \mathrm{CO}_{2}, \mathrm{H}_{2}$, and $\mathrm{H}_{2} \mathrm{O}$. This is a consequence of the reduction of the iron ore. The second set of phases are present in the iron ore which contains iron-rich minerals such as hematite and magnetite, as well as impurities $\left(\mathrm{SiO}_{2}, \mathrm{Al}_{2} \mathrm{O}_{3}, \mathrm{CaO}\right.$, $\mathrm{MgO}, \mathrm{Na}_{2} \mathrm{O}, \mathrm{K}_{2} \mathrm{O}, \mathrm{P}_{2} \mathrm{O}_{5}$, and $\mathrm{S}$ ) in various solid forms. The third is the metallurgical coke injected at the top of the $\mathrm{BF}$ which contains impurities such as ashes, sulfur, and water. The fourth is the flux $\left[\mathrm{CaMg}\left(\mathrm{CO}_{3}\right)_{2}, \mathrm{CaO}\right.$, $\mathrm{MgO}$, and $\mathrm{CaF}_{2}$ ] also introduced at the top of the $\mathrm{BF}$ and used ultimately to remove different impurities. The fifth is the slag which is formed intentionally at the bottom of the BF by introducing fluxes to help in removing undesirable impurities. The sixth is the metallic liquid solution (pig iron) which is the final valuable product of the BF. In considering the engineering design of such reactors, refractory materials used to protect the inside of the $\mathrm{BF}$ from chemical attack of the different phases can also be considered as important phases. For a given iron ore chemical composition, the control of the quality of the pig iron is assumed to be dictated mainly 
by the local equilibrium established at the bottom of the $\mathrm{BF}$ between the pig iron and the slag phase. Partitioning of the impurities between the liquid pig iron and the slag will depend on the chemical composition of the slag phase as well as the temperature and pressure.

Despite accumulated knowledge and experience, the continuous control optimization of the performance of a $\mathrm{BF}$ is still a difficult task. This is because iron ore chemical compositions are not known exactly and are not invariant over operating periods. Iron ore from different sources can be used at subsequent periods of the year depending on availability. Moreover, other variables not directly related to the chemical composition of the materials used in the BF will also modify the physicochemical behavior and hence the productivity of the BF. These include the sinter percentage of the iron pellets used in the BF, the blast pressure, the heat losses, the burden charging rate, the burden permeability, the burden distribution practices, the no. of casting, etc.

For these reasons, intensive research has been undertaken by scientists and engineers to model the BF process, in total or in part, using various numerical methods and tools. The current authors are aware of the abundant knowledge of the modeling of the BF. Comprehensive reviews on this subject may be found, for example, in the study of Ghosh and Majumdar. ${ }^{[1]} \mathrm{A}$ nonexhaustive list of the different approaches that can be used to model a BF may include the following:

(1) Mathematical models such as discrete element method $^{[2]}$ or finite volume methods ${ }^{[3,4]}$ used to simulate chemical kinetics and transport phenomena.

(2) Binary coding support vector machines algorithm, ${ }^{[1,5,6]}$ neural network models, ${ }^{[7-10]}$ and genetic algorithms ${ }^{[11,12]}$ all based on data-mining methods and used to help optimizing control parameters of the BF.

(3) Heat and mass balance models. ${ }^{[13]}$

(4) Thermodynamic (or equilibrium) models. ${ }^{[14,15]}$

Finite volume methods are attractive techniques if precise temperature, pressure, chemical composition, and flow profiles are to be evaluated throughout the BF; this is at the expense of a precise knowledge of several boundary conditions (chemical composition of the slag and of the pig iron) and physical properties (viscosity, density, surface tension, and thermal conductivity). The general idea behind data-mining methods is to use historical process data to build a black-box model constructed by an online learning process. Here, a screening of the variable model inputs is performed during the process. For metallurgical processes where classical fundamental thermochemical and physical laws apply, such an approach might provide reasonable results in the mathematical space bounded by the set of data used to construct the model; it will not, however, be useful when trying to extrapolate the behavior of the $\mathrm{BF}$ into unexplored operating conditions. This approach will thus be less helpful in solving engineering problems that need a fundamental understanding of the basic physicochemical phenomena. Moreover, several authors ${ }^{11,5,10]}$ do not distinguish the notion of adjustable input parameters (blast temperature, chemical composition of the iron ore, input amount of metallurgical coke, input amount of $\mathrm{O}_{2}$-enrich air, etc.) with output variables of the process $\left(\mathrm{CO} / \mathrm{CO}_{2}\right.$ ratio in the exhaust gas, and Si content in the liquid pig iron) that cannot be directly adjusted in actual operations. For example, the $\mathrm{CO} / \mathrm{CO}_{2}$ ratio in the exhaust gas is directly related to the amount of metallurgical coke used in the BF. Its value depends on the amount of hot blast air used, the local equilibrium conditions of temperature and pressure to which the exhaust gas is exposed as well as the other phases in equilibrium with this gas phase before it leaves the $\mathrm{BF}$, the exhaust gas speed, the chemical composition of the iron ore, the global heat balance of the reactor, etc. Taken as a variable of the black-box model, the $\mathrm{CO} /$ $\mathrm{CO}_{2}$ ratio will be directly correlated to the variables mentioned previously which will create a physically meaningless model.

Many of the problems quoted previously can be overcome using a thermodynamic classical model. Boundary conditions can be obtained for finite volume methods if a complete overall heat and mass balance is performed using classical thermodynamics calculations along with adequate input/output streams. Key and complex chemical reactions basics to several problems can be identified from classical thermodynamic calculations. If defined correctly, a minimum no. of input, output and recycling streams, as well as equilibrium reactors, will be used to simulate the BF in the current study. The success of this simulation strategy lies in four ingredients: (1) a good thermodynamic description of all the potentially stable phases observed in the complex chemical system of interest; (2) a robust Gibbs free energy minimization algorithm to determine the equilibrium state of complex multicomponent and multiphase systems; (3) a tool to manage the thermodynamic properties of each stream and reactor during the simulation, and (4) a numerical method for exploring and optimizing the various input streams properties to solve simultaneously mass and heat balances and to meet all the requirements of the BF. In the current study, the thermodynamic description of each potentially stable phase derives from FactSage software databases, ${ }^{[16]}$ with the exception of the Gibbs free energy of metallurgical coke (also defined as amorphous carbon) which is formulated in Section II-A. The numerical algorithm used to perform all the equilibrium calculations is SOLGASMIX developed by Eriksson. ${ }^{[17,18]}$ Streams, reactors, and heat exchangers are managed using the SimuSage software tool. ${ }^{[19]}$ Finally, a mesh adaptive direct search (MADS) algorithm designed for nonsmooth multi-objective optimization problems is used to optimize the properties of the different streams to find the optimal set of parameters for the simulated BF.

The simulation approach proposed in the current study is intended to provide to the metallurgical scientific community a precise thermodynamic scheme that can be used to optimize quickly the operating parameters of the $\mathrm{BF}$ according to thermodynamic considerations for any iron ore, provided that thermodynamic databases describing the Gibbs free energy function of each potentially stable phase of the considered multicomponent 
system are available. After the setup of such a simulation flow sheet using the different numerical tools enounced previously, the process parameters of the BF considered in the current study could be optimized according to particular needs of engineers or scientists. Moreover, this simulation flow sheet could be used as an efficient tool to provide boundary conditions for finite element simulations or as a black-box function for datamining methods.

The current study on the thermodynamic simulation of the BF comprises sections as follows: the formulation of the Gibbs free energy function of metallurgical coke is presented in Section II-A; the MADS algorithm used to perform black-box optimization during the course of the simulation process is explained in Section II-B; the origin of the slag formation in the $\mathrm{BF}$ and the thermodynamic justifications that motivated our simplified thermodynamic simulation approach of this industrial process are given in Section III-A; the thermodynamic simulation approach used to model the $\mathrm{BF}$ as well as the global optimization strategy to solve simultaneously the mass and heat balances of this system are explained in Section III-B. Finally, several results obtained from this thermodynamic simulation approach are presented in Section IV.

\section{METHODOLOGY}

\section{A. Simplified Formulation of the Gibbs Free Energy Function of Metallurgical Coke}

Throughout the current study, carbon is used in the $\mathrm{BF}$ as the reducing agent source. Carbon of suitable reactivity and physical strength used in $\mathrm{BF}$ for the smelting of iron is obtained from the destructive distillation of selected coals. ${ }^{[20]}$ Metallurgical (or amorphous) coke is obtained from this operation. Metallurgical coke is often considered to be a heterogeneous material consisting of graphite and amorphous carbon, its degree of crystallinity depending on the calcination temperature. Feret ${ }^{[21]}$ presented a review as well as a newly conceived approach for evaluating experimentally the degree of graphitization (DOG) of petroleum coke for low-temperature graphitization processes $[1473 \mathrm{~K}$ to $1773 \mathrm{~K}\left(1200{ }^{\circ} \mathrm{C}\right.$ to $\left.\left.1500{ }^{\circ} \mathrm{C}\right)\right]$. The author reported a DOG of petroleum coke of 15 pct for these conditions, which could be a first rough estimate for metallurgical coke in the lower part (LP) of the BF. Jiménez Mateos et $a l^{[22]}$ reported $d_{002}$ interlayer distances of calcined petroleum coke at different temperatures $[753 \mathrm{~K}$ to $3073 \mathrm{~K}\left(480{ }^{\circ} \mathrm{C}\right.$ to $\left.2800{ }^{\circ} \mathrm{C}\right)$ ] for sulfur-saturated specimens. Using the ASTM norm to define the crystallinity $g$ of coke,

$$
g=\frac{(0.3440 \mathrm{~nm})_{\text {amorphous }}-\left(d_{002}\right)_{\text {coke }}}{(0.3440 \mathrm{~nm})_{\text {amorphous }}-(0.3354 \mathrm{~nm})_{\text {graphite }}}
$$

Coke exposed to a temperature of $1873 \mathrm{~K}\left(1600^{\circ} \mathrm{C}\right)$ would have a degree of crystallinity of $\approx 12$ pct. Dong et $a .^{[23]}$ measured $d_{002}$ interlayer distances for tuyere-level core-drill coke samples from BF operation. In this case, the application of the ASTM norm cannot be performed as all their $d_{002}$ measurements are $>0.344 \mathrm{~nm}$. Another characteristic measurement, the stacking height of the lattice planes $L_{\mathrm{c}}$, is reported by these authors and varies between 4.7 and $6.2 \mathrm{~nm}$ for their specimens. Lundgren et al. ${ }^{[24]}$ performed similar measurements and obtained values ranging between 2 and $14 \mathrm{~nm}$. Even though there is no direct correlation between $L_{\mathrm{c}}$ and $g$, the previously quoted experimental data are of similar magnitude as the coke samples analyzed by Jiménez Mateos et al. ${ }^{[22]}$ Experiments of Lundgren et al. ${ }^{[24]}$ were performed in a range of temperatures comprised between $1573 \mathrm{~K}$ and $2173 \mathrm{~K}$ $\left(1300{ }^{\circ} \mathrm{C}\right.$ and $1900^{\circ} \mathrm{C}$ ) (close to the BF conditions) and have a degree of crystallinity between 0 and 12 pct. From this section, it can be concluded that different origins and processing routes of the respective parent feedstocks for petroleum coke and metallurgical coke may be a reason for the differences in their macromolecular structures. It is therefore assumed in the current study that metallurgical coke, under BF conditions, is likely to be amorphous.

The Gibbs free energy function that should be considered in a $\mathrm{BF}$ is therefore the one of amorphous carbon. As will be shown later, the consideration of the Gibbs free energy of coke instead of graphite will modify the transition temperature of the Boudouard reaction:

$$
\mathrm{C}(s)+\mathrm{CO}_{2}(g) \rightarrow 2 \mathrm{CO}(g),
$$

where $\mathrm{CO}$ becomes dominant. As a result, the equilibrium state in the higher part (HP) of the $\mathrm{BF}$ could be shifted by considering coke or graphite in the equilibrium calculations.

The activity of carbon in coke relative to graphite was measured by Jacob and Seetharaman ${ }^{[25]}$ using a solidstate galvanic cell. The results are presented in Figure 1 and are used in the current study to validate the theoretical Gibbs free energy function of metallurgical coke presented in Appendix 1. In the range of studied temperature $\left[955 \mathrm{~K}\right.$ to $1245 \mathrm{~K}\left(682{ }^{\circ} \mathrm{C}\right.$ to $\left.\left.972{ }^{\circ} \mathrm{C}\right)\right]$ it is assumed that the crystallinity of coke will be minimal according to the previous discussion. Appendix 1 of the current study provides a fundamental scientific justification of each thermodynamic parameter used to define the Gibbs free energy of amorphous carbon. The molar Gibbs free energy difference due to amorphization of graphite $\Delta g^{g . \rightarrow a}(T)$ can be written as follows:

$$
\begin{aligned}
\Delta g^{g . \rightarrow a \cdot}(T) & =\Delta h^{g . \rightarrow a \cdot}\left(T_{0}\right)+\int_{T_{0}}^{T} \Delta c_{P}^{g \cdot \rightarrow a \cdot}\left(T^{\prime}\right) \mathrm{d} T^{\prime} \\
& -T \Delta s^{g \cdot \rightarrow a \cdot}\left(T_{0}\right)-T \int_{T_{0}}^{T} \frac{\Delta c_{P}^{g \cdot \rightarrow a \cdot}\left(T^{\prime}\right)}{T^{\prime}} \mathrm{d} T^{\prime},
\end{aligned}
$$

where $T_{0}=298 \mathrm{~K}\left(25^{\circ} \mathrm{C}\right)$ is the standard temperature, $\Delta h^{g . \rightarrow a}=13.6 \mathrm{~kJ} \mathrm{~mol}^{-1}, \Delta s^{g . \rightarrow a}=1.663 \mathrm{~J} \mathrm{~mol}^{-1} \mathrm{~K}^{-1}$, and $\Delta c_{P}^{g . \rightarrow a .}=1 \mathrm{~J} \mathrm{~mol}^{-1} \mathrm{~K}^{-1}$ are, respectively, the molar enthalpy, entropy, and heat capacity change due to 


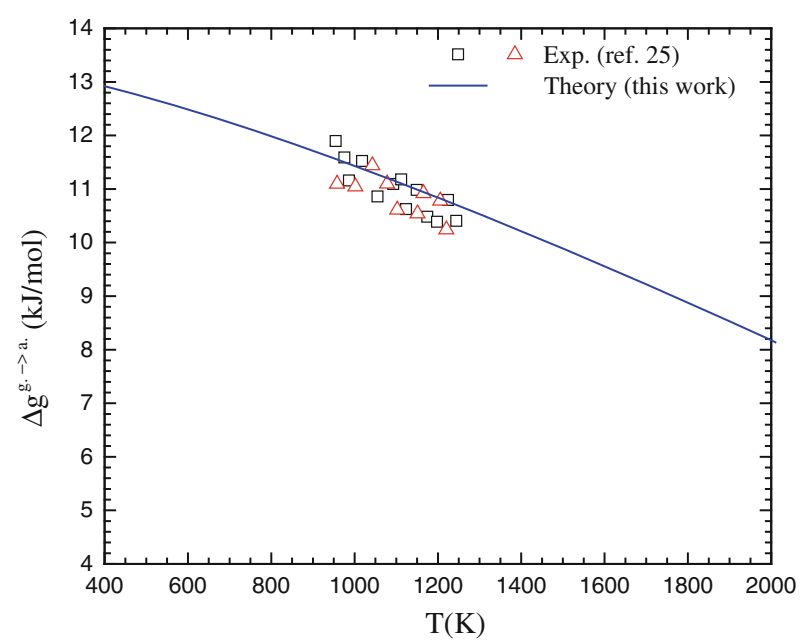

Fig. 1-Comparison between the theoretical formulation of the Gibbs free energy of amorphous carbon and experimental data of Jacob and Seetharaman. ${ }^{[25]}$

amorphization of graphite. Details of the estimation of these three quantities are given in Appendix 1.

\section{B. MADS Algorithm}

As mentioned previously, a black-box optimization algorithm called MADS is used in the current study to identify several optimal operating conditions of the BF during a simulation. The MADS algorithm ${ }^{[26]}$ is designed to solve optimization problems of the following forms:

$$
\min _{x \in \Omega} f(x)
$$

with

$$
\begin{gathered}
f: \Re^{n} \rightarrow \Re \cup\{\infty\} \\
\Omega=\left\{x \in X: c_{j}(x) \leq 0, j \in \boldsymbol{J}=\{1,2,3 \ldots m\}\right\},
\end{gathered}
$$

where $X$ is a subset of $\Re^{n}$ and $c_{j}(x)$ are $m$ constraint functions from $\Re^{n}$ to $\Re \cup\{\infty\}$. The functions $f$ and $c_{j}(x), j \in \boldsymbol{J}$ are usually evaluated from costly black-box simulations for which no derivative information is available. In this context, we consider derivative-free optimization methods ${ }^{[27]}$ which include algorithms such as MADS or the Generalized Pattern Search method. ${ }^{[28]}$

MADS is an iterative algorithm where each iteration $k$ contains three steps: the search, the poll, and the updates. During the search and the poll steps, candidate points are generated on a discretization of the space called the mesh, and the functions are evaluated at these locations. The mesh $M_{k}$ at iteration $k$ is defined by the following equation:

$$
M_{k}=\left\{x+\Delta_{k} D_{Z}: x \in V_{k}, z \in \Re^{n_{D}}\right\} \subset \Re^{n},
$$

where $V_{k}$ is the set of evaluated points at the start of iteration $k, D \in \Re^{n}$ is a set of positive spanning directions typically set to the basis directions, $n_{D}$ is the no. of directions, and $\Delta_{k}$ is the mesh size parameter which dictates the coarseness of the mesh.
The search step is the flexible part of the method. It is optional and allows for the generation of solutions anywhere on $M_{k}$, thus permitting global exploration and diversification. It can be generic, such as Latin Hypercube sampling, ${ }^{[29]}$ or problem-specific, when defined by the user with some knowledge of the black-box function topology. The poll step is mandatory and is more rigidly defined since it ensures the convergence of the method. It provides intensification by searching around the current iterate using directions that form a positive spanning set. While classic pattern search methods use a finite no. of these directions, MADS defines a dense set of directions, meaning that potentially any direction of the space can be explored. At the end of each iteration, if no candidate improved the current solution, the mesh size is reduced by a rational factor and the current iterate is kept. If a new solution has been found, then the mesh size is augmented, and the current iterate is changed. MADS is one of the few derivative-free optimization methods dealing with general constraints not just by ignoring infeasible points. It does so, and with no penalty parameter, by considering a filter-like strategy called the progressive barrier. ${ }^{[30]}$

MADS is not a heuristic method since theoretical convergence is proven based on the Clarke calculus for nonsmooth functions. ${ }^{[31]}$ This theory proves that, under mild hypotheses, convergence to a locally optimal solution is ensured. Finally, the MADS algorithm ${ }^{[26]}$ provides an implementation with the most recent algorithmic developments, such as bi-objective optimization, sensitivity analysis, surrogate management, categorical and integer variables, parallelism, etc.

\section{THERMODYNAMIC SIMULATION OF THE BF}

\section{A. Slag Formation in the BF}

Slag formation in BF most probably originates from the fusion of clay minerals or other low-melting compounds present in the gangue of the original iron ore, the added fluxes and the coke. ${ }^{[32]}$ In this section, we present one potential slag formation mechanism in a $\mathrm{BF}$ considering the use of nonfluxed and nonsintered iron ores. It should be pointed out that different iron ore physicochemical property assumptions would result in a different proposed slag formation mechanism. Alkali oxides such as $\mathrm{Na}_{2} \mathrm{O}$ are present in small amounts in iron ores but can still noticeably alter their softening and melting properties. For typical iron ores containing equivalent quantities of $\mathrm{Fe}_{2} \mathrm{O}_{3}, \mathrm{SiO}_{2}, \mathrm{Al}_{2} \mathrm{O}_{3}$, and alkali oxides, classical thermodynamic calculations predict that alkali oxides will first react with $\mathrm{SiO}_{2}$ to form a low-temperature silica-rich eutectic liquid. Figure A1 presented in Appendix 2 of the current study shows the $\mathrm{Na}_{2} \mathrm{O}-\mathrm{SiO}_{2}$ phase diagram. The lowest eutectic temperature in the silica-rich side of this diagram occurs, using the thermodynamic database considered in the current study, at $1066 \mathrm{~K}\left(793{ }^{\circ} \mathrm{C}\right)\left(\mathrm{Na}_{6} \mathrm{Si}_{8} \mathrm{O}_{19}+\mathrm{SiO}_{2} \rightarrow\right.$ Liq. $)$. This is the minimal slag formation temperature expected for such iron ores if no solid-solid reaction between 
$\mathrm{FeO}$-wüstite and $\mathrm{SiO}_{2}$-quartz occur in this range of temperature, i.e., if (1) fayalite $\left(\mathrm{Fe}_{2} \mathrm{SiO}_{4}\right)$ and ferrosilite $\left(\mathrm{FeSiO}_{3}\right)$ are assumed not to form in the iron ore in this range of temperature, and (2) no $\mathrm{FeO}$ dissolves in the slag.

Figure 2 shows the evolution of the slag amounts of some hypothetical iron ores containing $\mathrm{SiO}_{2}, \mathrm{Al}_{2} \mathrm{O}_{3}$, and $\mathrm{Na}_{2} \mathrm{O}$ in equilibrium with metallic iron (body-centered cubic, face-centered cubic, or liquid depending on the equilibrium temperature) heated from $1000 \mathrm{~K}$ to $1800 \mathrm{~K}$ $\left(727^{\circ} \mathrm{C}\right.$ to $1527^{\circ} \mathrm{C}$ ) as predicted from different thermodynamic calculations. First, it is to be noted that small amount of $\mathrm{FeO}$ dissolved in the slag will lower the pseudo-binary $\mathrm{Na}_{2} \mathrm{O}-\mathrm{SiO}_{2}$ eutectic temperature to $1058 \mathrm{~K}\left(785^{\circ} \mathrm{C}\right)$ when fayalite and ferrosilite are considered not to form in the system. Also, depending on the $\mathrm{Al}_{2} \mathrm{O}_{3}$ equivalent wt pct present in the iron ore, this temperature can noticeably be either increased or decreased. If enough $\mathrm{Al}_{2} \mathrm{O}_{3}$ is "available" in the iron ore to trap completely $\mathrm{Na}_{2} \mathrm{O}$ in the form of albatite $\left(\mathrm{NaAlSi}_{3} \mathrm{O}_{8}\right)$ and nepheline $\left(\mathrm{NaAlSiO}_{4}\right)$, then the slag will start to form at around $1201 \mathrm{~K}\left(928{ }^{\circ} \mathrm{C}\right)$ as can be seen in Figure 2. An insufficient equivalent amount of $\mathrm{Al}_{2} \mathrm{O}_{3}$ in the iron ore to completely trap $\mathrm{Na}_{2} \mathrm{O}$ will result in an opposite effect, i.e., the appearance of a slag phase to a lower temperature of $1011 \mathrm{~K}\left(738^{\circ} \mathrm{C}\right)$.

When fayalite is considered in the equilibrium calculations, less $\mathrm{SiO}_{2}$ is available to react with $\mathrm{Na}_{2} \mathrm{O}$ to form a slag phase. For an iron ore that does not contain $\mathrm{Al}_{2} \mathrm{O}_{3}$, the slag will start to form at $1172 \mathrm{~K}\left(899^{\circ} \mathrm{C}\right)$. Again, $\mathrm{Al}_{2} \mathrm{O}_{3}$ could potentially increase or decrease the minimal temperature of slag formation whether it is present in sufficient amount $\left[T=1319 \mathrm{~K}\left(1046{ }^{\circ} \mathrm{C}\right)\right]$ or not $\left[T=1106 \mathrm{~K}\left(833{ }^{\circ} \mathrm{C}\right)\right]$. Also, $\mathrm{Na}_{2} \mathrm{O}$ is partially soluble in FeO-wüstite. ${ }^{[33]}$ These experimental data were not considered in the construction of the thermodynamic databases used in the current study. It implies that no thermodynamic parameter to model this solid solubility was introduced into the thermodynamic

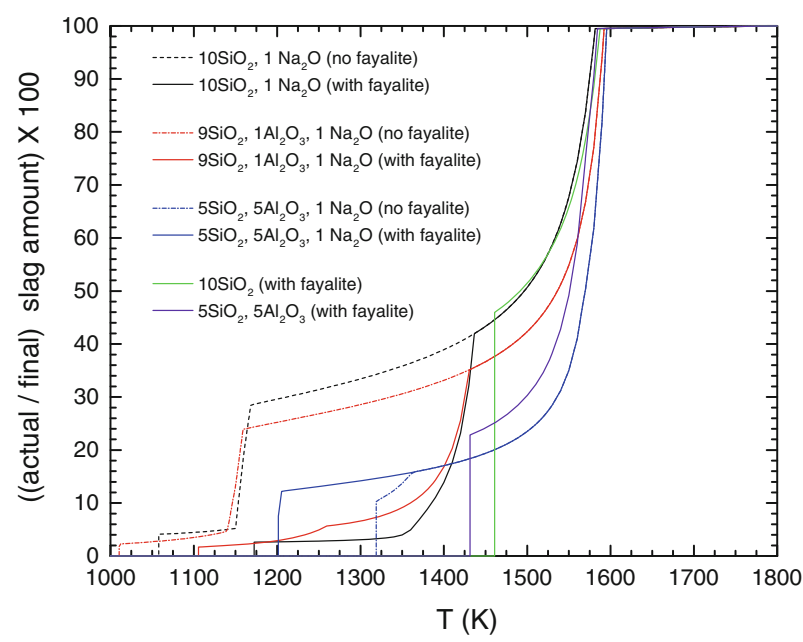

Fig. 2-Evolution of the relative acidic slag amount (no flux) of various iron ores ( $\mathrm{FeO}$ basis) as a function of temperature with (solid lines) and without (dashed and dotted lines) formation of fayalite (thermodynamic activity of $\mathrm{Fe}(\mathrm{BCC} / \mathrm{FCC} /$ liq.) $=1)$. model describing the FeO-monoxide solid solution. Preliminary thermodynamic calculations considering this solid solution have shown that if $\mathrm{Na}_{2} \mathrm{O}$ is present in sufficiently low amounts in the original iron ore, i.e., around $400 \mathrm{ppm}$ by weight, then the formation of a $\mathrm{Na}_{2} \mathrm{O}-\mathrm{SiO}_{2}$-rich liquid at low temperature can be delayed. If alkali oxides are below this concentration, then an acidic slag will start to form inside the non-selffluxed iron ore pellet particles at a substantially higher temperature of about $1461 \mathrm{~K}\left(1188{ }^{\circ} \mathrm{C}\right)$ if no $\mathrm{Al}_{2} \mathrm{O}_{3}$ is present and to about $1431 \mathrm{~K}\left(1158{ }^{\circ} \mathrm{C}\right)$ if $\mathrm{Al}_{2} \mathrm{O}_{3}$ is present. This can be seen in the $\mathrm{FeO}-\mathrm{SiO}_{2}$ phase diagram presented in Figure A2 in Appendix 2.

Such an acidic slag is believed to be expelled from non-self-fluxed iron ore pellets at some point in the reduction process in the higher part of the blast furnace. This typical acidic slag does not define the final chemical composition of the slag removed from the bottom of the BF. In order to separate these acidic slag impurities from the liquid pig iron and ultimately remove them from the process, a basic fluxing agent such as $\mathrm{CaO}$ is also introduced in the feedstock of the BF. When expelled from these pellet particles (breaking of the metallic iron shell), this acidic slag will be exposed to both severe reducing conditions [which will cause the $\mathrm{FeO}$ of the (initially acidic) slag to be reduced to metallic iron] and flux particles (which will react with $\mathrm{SiO}_{2}$ to form stable solid oxides), resulting in an abrupt decreases of the slag amount in the system. The basic slag observed at the bottom of the BF in equilibrium with the molten metal will finally be produced if a sufficiently high temperature is imposed to the system. The lowest eutectic temperature of the $\mathrm{CaO}-\mathrm{SiO}_{2}$ system is at $1710 \mathrm{~K}\left(1437^{\circ} \mathrm{C}\right)$ according to Figure A3 presented in Appendix 2 while the lowest eutectic temperature in the $\mathrm{Al}_{2} \mathrm{O}_{3}-\mathrm{SiO}_{2}-\mathrm{CaO}$ predicted from the thermodynamic assessment used in the current study is $1457 \mathrm{~K}\left(1184{ }^{\circ} \mathrm{C}\right)$ (Figure A4 in Appendix 2).

In modern blast furnaces, it is highly desirable to limit the range of temperature where a slag phase can form to maximize the softening temperature and to bring it close to the melting temperature of the burden, i.e., to narrow the softening and melting temperature interval to (1) facilitate the formation of a low and thin cohesive zone, (2) enlarge the thermal reserve zone and (3) reduce the resistance to gas flow in this zone. ${ }^{[34]}$ To attain these objectives, iron ore pellets can be prereduced at low temperature where slag is not forming and self-fluxed with $\mathrm{CaO}$. Under these conditions, the appearance of slag droplets is expected, if $\mathrm{FeO}$ is completely reduced, at temperatures close to the lowest eutectic temperatures of the $\mathrm{CaO}-\mathrm{SiO}_{2}$ pseudo-binary system. These are $1710 \mathrm{~K}$ and $1737 \mathrm{~K}\left(1437^{\circ} \mathrm{C}\right.$ and $\left.1464{ }^{\circ} \mathrm{C}\right)$ depending on the basicity of the slag if $\mathrm{Al}_{2} \mathrm{O}_{3}$ is not present. If $\mathrm{Al}_{2} \mathrm{O}_{3}$ is present, such temperatures start at $1457 \mathrm{~K}$ $\left(1184^{\circ} \mathrm{C}\right)$ [1456 $\mathrm{K}\left(1183^{\circ} \mathrm{C}\right)$ if the slag can dissolve some $\mathrm{FeO}]$ and are a function of the overall composition of the equivalent oxide system defining the local equilibrium conditions. Figure 3(a) presents the evolution of the temperature of slag formation as a function of the degree of reduction expressed as weight ratio (metallic $\mathrm{Fe} /$ total $\mathrm{Fe}$ ) for different self-fluxed iron ores. 


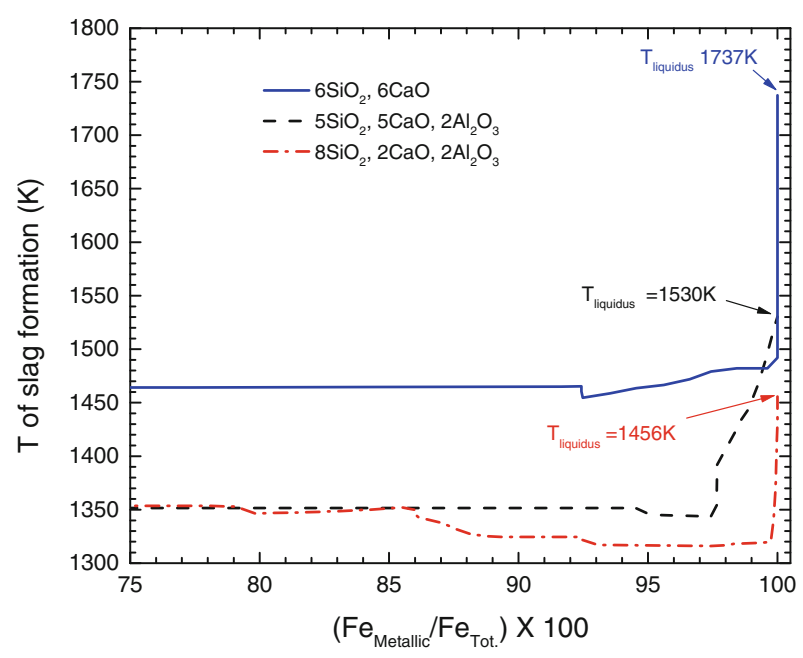

(a)

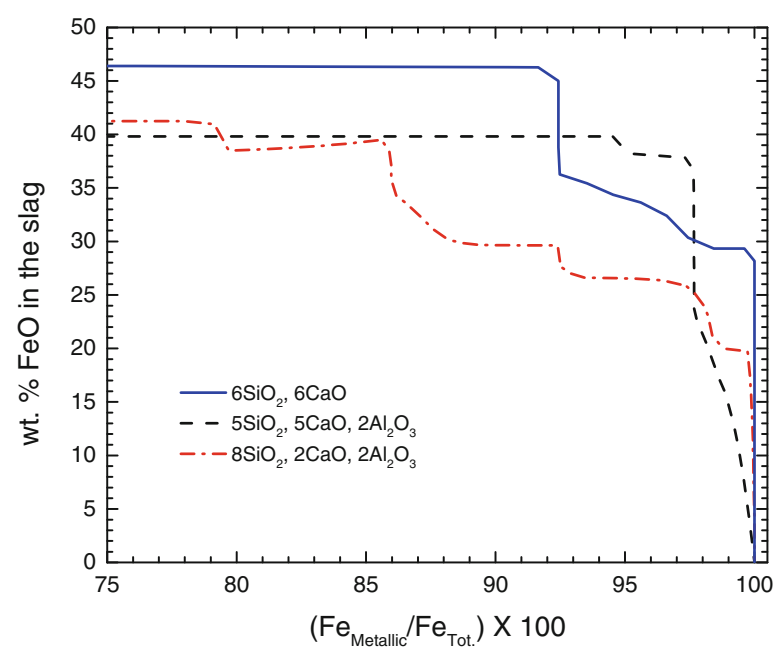

(b)

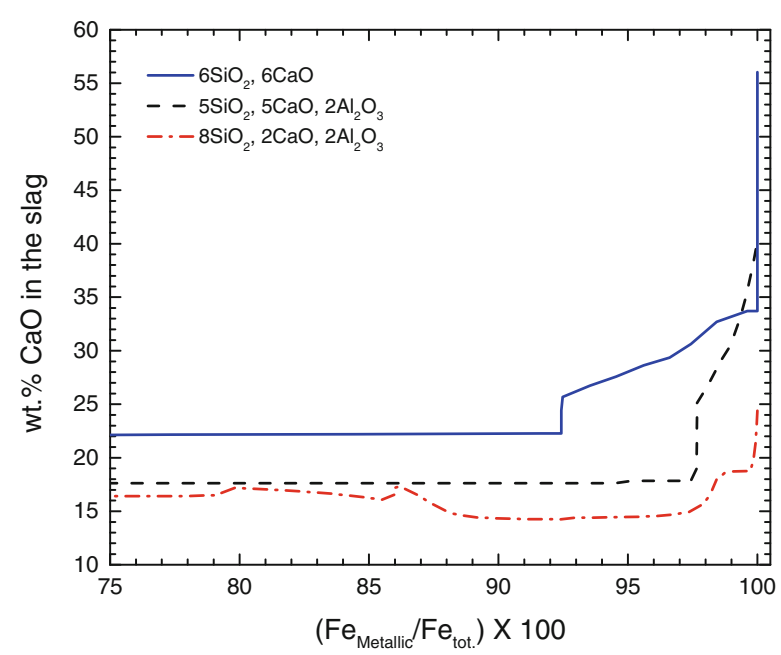

(c)

Fig. 3-Evolution of (a) the temperature of slag formation; $(b)$ the $\mathrm{FeO}$ wt pet in the slag; and $(c)$ the $\mathrm{CaO}$ wt pet in the slag for different iron ores ( $\mathrm{FeO}$ basis) in equilibrium with metallic iron as a function of the degree of reduction expressed as the weight ratio (metallic $\mathrm{Fe} /$ total $\mathrm{Fe}$ ).
When the available wüstite of the iron ore is reduced, the available amount of $\mathrm{FeO}$ for the slag phase decreases until all the iron of the system is fully reduced (Figure 3). Recent experiment concerning the softening and melting properties of prereduced and prefluxed pellets where no alkali oxides are present confirm this rationale. ${ }^{[34]}$

From this section, it can be concluded that the range of temperature where a slag phase is thermodynamically stable in a BF depends strongly on the iron ore chemical composition (the presence or the absence of alkali oxide, self-fluxed or not, prereduced or not, etc.) used in the blast furnace, as well as the local equilibrium conditions of temperature and imposed oxygen partial pressure. This range of temperature could be as broad as $1058 \mathrm{~K}$ to $1800 \mathrm{~K}\left(785^{\circ} \mathrm{C}\right.$ to $\left.1527^{\circ} \mathrm{C}\right)$. Therefore, it has been decided not to try to simulate the entire slag formation process but rather only to consider the final equilibrium at $1800 \mathrm{~K}\left(1527^{\circ} \mathrm{C}\right)$ where the slag phase is in equilibrium with the molten pig iron. For the overall mass and heat balances, this assumption has no influence on the precision of the final results.

\section{B. Thermodynamic Simulation Process of the BF}

The thermodynamic simulation of the BF is designed in the current study in a specific way to allow the precise theoretical evaluation of all the important input variables that directly affect, from a thermodynamic standpoint only (e.x.: no kinetics factors), all the important local equilibrium states attained during the continuous service of the BF. All the input variables presented in the current study are defined on a one-metric-ton-liquidiron-production basis. For the current study, the original input variables are the amount of injected coke in the reactor, and the composition and amount of the $\mathrm{O}_{2}$-enriched air introduced at the tuyere level in the $\mathrm{BF}$. Unlike conventional techniques ${ }^{[13,15]}$ that solve a combination of predetermined stoichiometric equations that define chemical reactions and mass balances and an explicit global enthalpy balance equation, the current simulation strategy takes full advantage of classical thermodynamics and considers simultaneously the potential presence of more than 120 phases (stoichiometric compounds, solid and liquid solutions, as well as a gas phase) for the Fe-Si-Al-Ca-C-O-N-H system. Several advantages arise from this approach: (1) No explicit sets of stoichiometric equations, equilibrium constant equations, and heat balance have to be defined and solved simultaneously to determine the optimized input parameters; (2) the presence of impurities such as sulfur, sodium, or potassium, which might not affect greatly the overall heat balance can be precisely accounted for during the calculations, providing essential information; (3) the thermodynamic model of any potentially stable phase considered in the calculations can be improved continuously without having to modify the general simulation scheme; and (4) the same thermodynamic database can be used to investigate, a posteriori, other phenomena such as refractory corrosion or, as in the current study, slag formation. 
The main objective of the current thermodynamic simulation process is to solve simultaneously the global mass and heat balance of the BF by varying strategically some of the global input (GI) stream amounts of the reactor and some equilibrium conditions using MADS and a thermodynamic-oriented strategy enounced in Section III-B-4. The GI streams identified in the current study are the stream of iron ore that contains impurities and fluxes (GI1), the coke stream (GI2), the $\mathrm{O}_{2}$-enriched blast air stream (GI3), and the auxiliary fuel of methane stream (GI4). In the current study, coke impurities such as ashes and volatiles are not considered, but could be added directly to stream GI2 without any other modification to the simulation process. This would improve the precision of final slag stream properties such as its produced amount and chemical composition. Pulverized coal, often used in geographic areas where natural gas is not readily available, could also substitute methane in stream GI4 without any change of the model structure. The simulation also generates Global Outputs (GOs) which are the valuable liquid pig iron product (GO2) and other waste streams such as the slag (GO1) and the exhaust gas which does not account for the potential presence of dust particle(s) (GO3).

The thermodynamic simulation of the important phase equilibria occuring in the continuous operation of the $\mathrm{BF}$ is done by defining three equilibrium reactors (R1, R2, and R3) for a BF virtually divided into a lower and a upper part. A detailed definition of the two zones defined in the current study is presented in Sections III-B-2 and III-B-3. The first equilibrium reactor (R1) defines the formation of the final slag and the liquid pig iron by the melting of the oxide impurities and of the completely reduced iron using the heat generated by the combustion of coke with $\mathrm{O}_{2}$-enriched hot air. This reactor is operated in adiabatic conditions $\left(Q_{\mathrm{R} 1}=\Delta H_{\mathrm{R} 1}=0\right)$. The second equilibrium reactor (R2) is operated in isothermal conditions and simulates the thermal reserve zone observed near the $1200 \mathrm{~K}$ $\left(927^{\circ} \mathrm{C}\right)$ isotherm in the BF. ${ }^{[13]}$ This is the zone where the iron ore is reduced to solid metallic iron saturated with carbon by the gas phase. The last equilibrium reactor (R3) simulates the fast cooling of the exhaust gas by the counter-current heat exchange with the cold iron ore. Reactors are connected by Intermediate Input (II) streams. Finally, cooling $(\mathrm{C})$ and heating $(\mathrm{H})$ units must be used to simulate equivalent heat transfers that occur in the BF. This straightforward representation of the BF is believed to be the simplest way of defining correctly mass and heat balances while considering all the potential phase equilibria in this system. A schematic representation of the original 4-unit thermodynamic representation of the BF and of the modified representation based on a 5-unit simulation process is presented in Figure 4. Differences between both approaches and the necessity of modifying the original 4-unit simulation process are given in Section III-B-2. All the streams and units presented in this figure are defined and detailed in Table I. In this table, all the input/output parameters of each stream and unit are presented as well as the set of phases considered in the equilibrium calculations of each reactor. These typical operating conditions are found in the study of Peacey and Davenport. ${ }^{[13]}$ These process parameters are most likely to have different

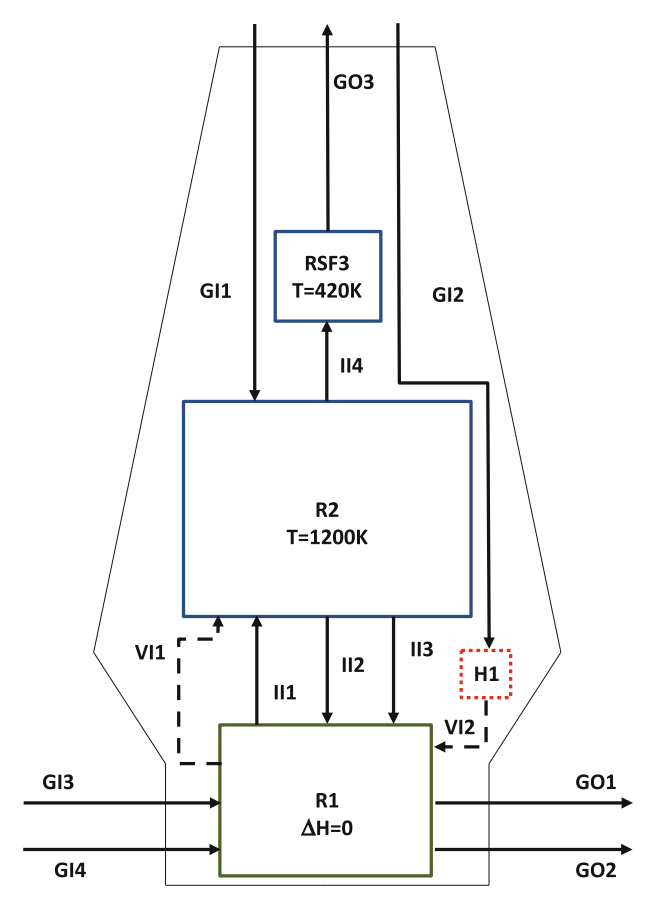

(a)

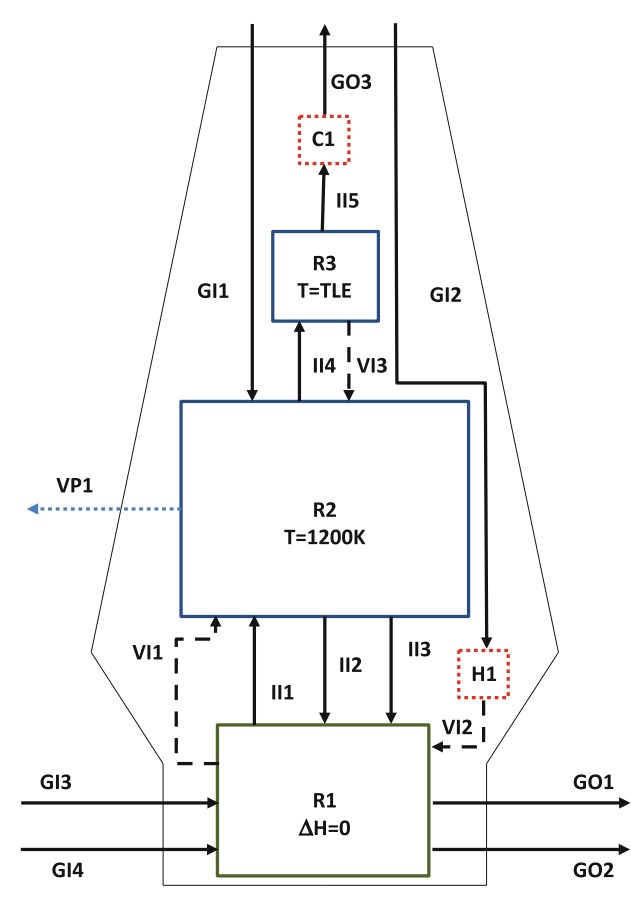

(b)

Fig. 4-Schematic representation of $(a)$ the 4-unit and $(b)$ the 5-unit thermodynamic process simulations of the blast furnace. 


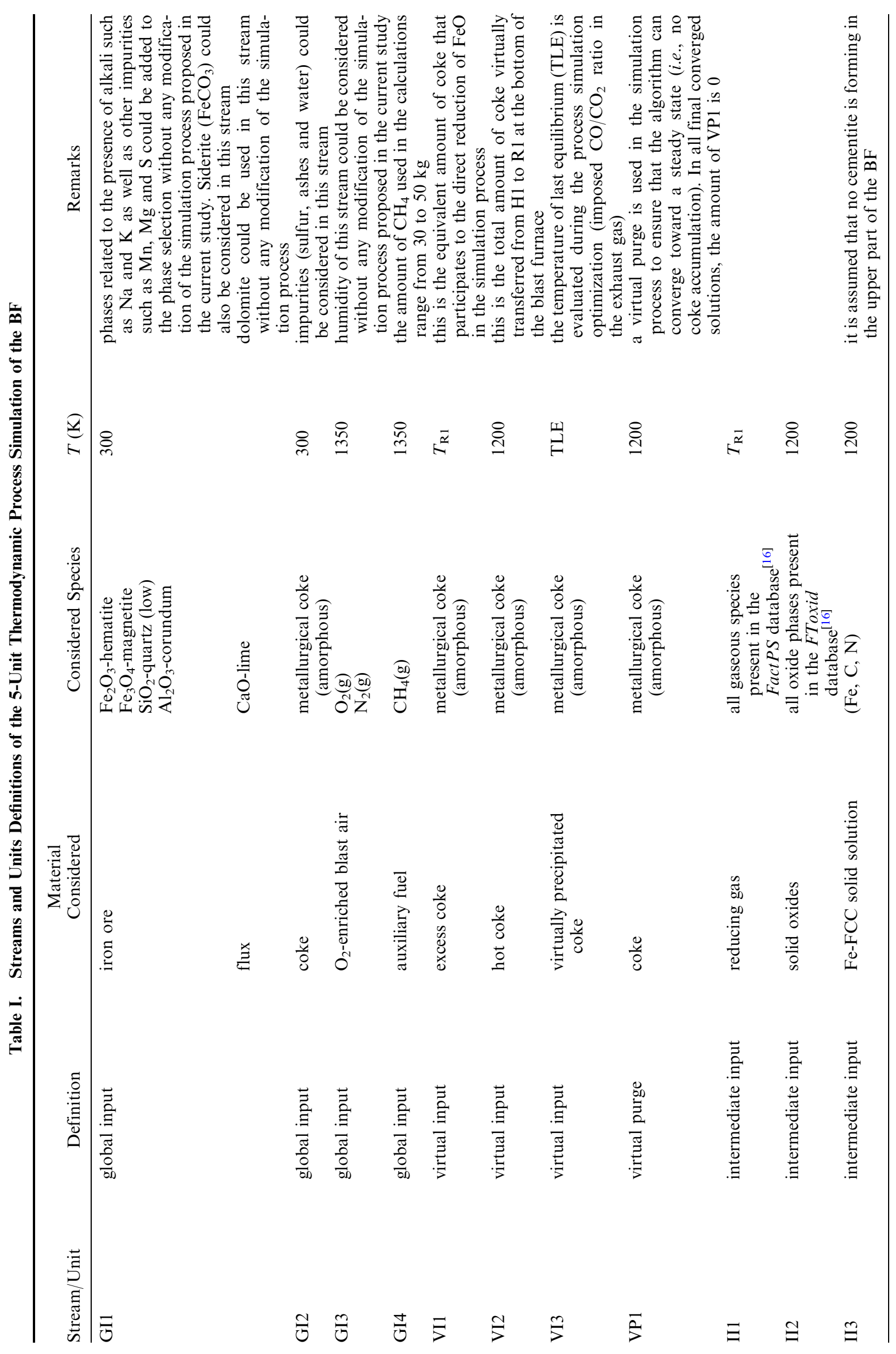




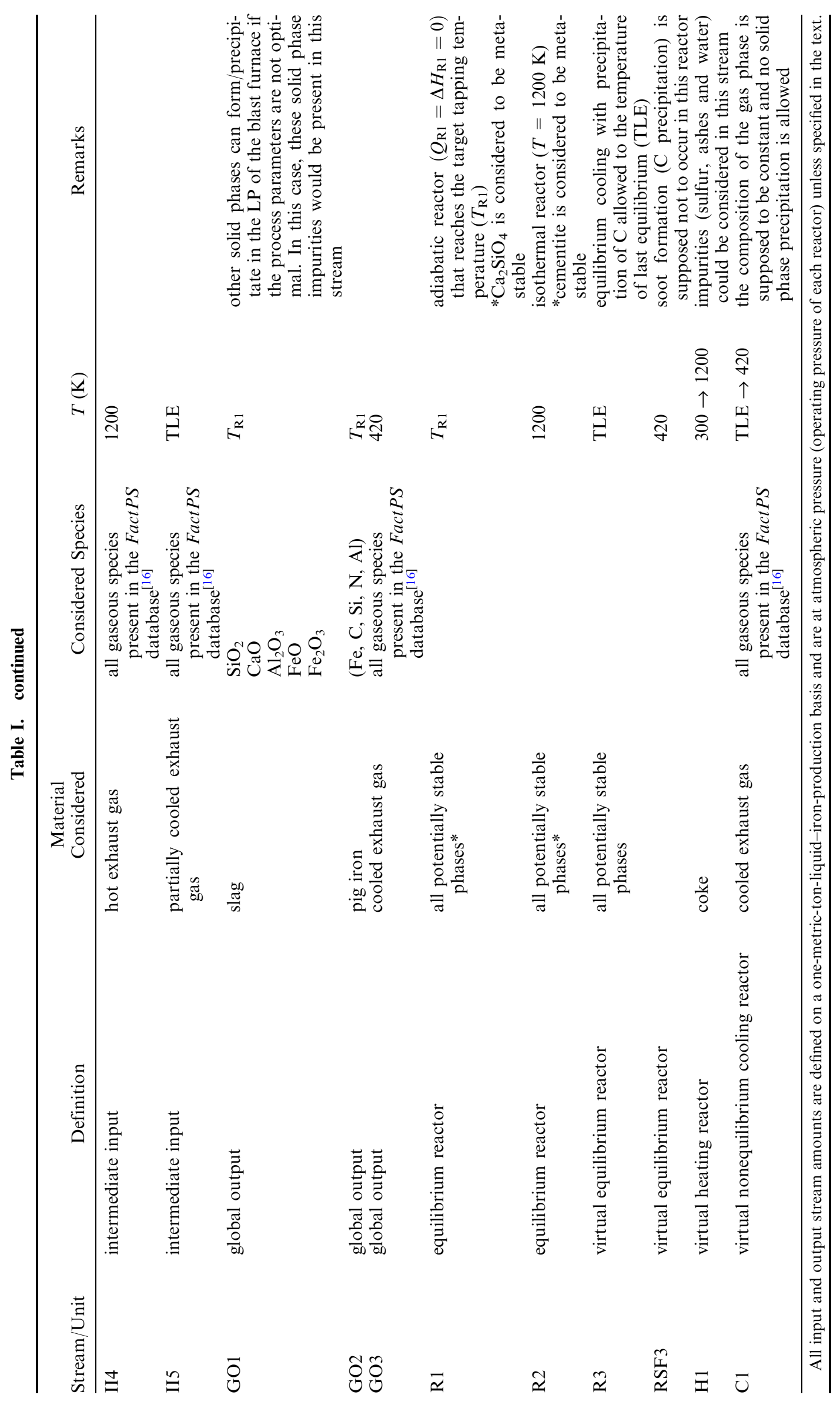




\begin{tabular}{lccccccr}
\hline & \multicolumn{9}{c}{ Wt pct } & & \\
\cline { 2 - 5 } Iron Ore ID & $\mathrm{Fe}_{2} \mathrm{O}_{3}$ & $\mathrm{Fe}_{3} \mathrm{O}_{4}$ & $\mathrm{SiO}_{2}$ & $\mathrm{Al}_{2} \mathrm{O}_{3}$ & $\mathrm{CaO}$ & Total Iron Ore Amount $(\mathrm{kg})$ & CaO Flux Amount $(\mathrm{kg})$ \\
\hline 1 & 89.9 & 0 & 6.3 & 3.8 & 0 & 1589.7 & 150 \\
2 & 94.7 & 0 & 3.3 & 2.0 & 0 & 1526.7 & 75 \\
3 & 34.9 & 56.8 & 7.4 & 0.9 & 0 & 1536.1 & 0 \\
4 & 91.4 & 1.6 & 2.5 & 0.4 & 4.1 & & 0 \\
\hline
\end{tabular}

* Self-fluxed iron ore.

values from one $\mathrm{BF}$ to another since kinetic factors and in-house data are taken into account upon their operation. Unless specified in subsequent sections, these conditions are used to generate all the results presented in Section IV. The chemical composition of each iron ore studied in the current study is given in Table II and has been no.ed (numbered) for subsequent identification in the text.

At the end of the simulation, the implemented procedure provides a set of optimized parameters and a list of all the phases and their respective amounts that exit the BF. This set of input and output data completely satisfies all the constraints related to mass and heat balances as well the other specific BF constraints detailed in Section III-B-4. Key assumptions considered in the establishment of the proposed simulation strategy of the BF are summarized as follows:

- No unreduced FeO enters R1. Therefore, no reduction of this FeO by the submerged coke column in the lower zone is considered.

- The equilibrium reactor $\mathrm{R} 2$ considers manifestations of both indirect and direct reduction of wüstite.

- No pulverized coal injection in the bottom of the BF is considered in this specific example.

- No coke impurities such as ashes and volatiles are considered in the feedstock of this specific example.

- Carbon saturation of the liquid pig iron is imposed by its equilibrium with amorphous carbon (metallurgical coke), not graphite.

- No dust particle(s) are exiting the BF.

- The target $\mathrm{CO} / \mathrm{CO}_{2}$ ratio of the cooled exhaust gas is assumed to be 1.045 .

- The slag phase is only produced in the bottom part of the BF (in R1).

- Cementite is considered as a metastable phase in the upper part of the BF.

- A target tapping temperature $T_{\mathrm{R} 1}$ of $1800 \mathrm{~K}$ $\left(1527^{\circ} \mathrm{C}\right)$ is used throughout the current study.

\section{Thermodynamic simulation of the lower part} of the $B F$

In the lower part of the $\mathrm{BF}$, heat is generated by the combustion of incandescent coke (VI2) with hot $\mathrm{O}_{2-}$ enriched air (GI3) to melt the solid iron (stream II3) and the solid oxides (stream II2). It also provides heat for the endothermic direct reduction by coke of $\mathrm{FeO}$ and some oxide impurities such as $\mathrm{SiO}_{2}$ and $\mathrm{MnO}$. It is modeled using a simple unit reactor (unit R1 in Figure 4) operating under adiabatic conditions. The overall chemical reaction at the origin of this heat generation is expressed as follows:

$$
\begin{aligned}
& \mathrm{C}(\text { coke })+1 / 2 \mathrm{O}_{2}(g) \rightarrow \mathrm{CO}(g) ; \quad \Delta h^{0}\left[1800 \mathrm{~K}\left(1527^{\circ} \mathrm{C}\right)\right] \\
& \quad=-132.5 \mathrm{~kJ} \mathrm{~mol}^{-1}
\end{aligned}
$$

In addition to coke which is introduced at the top of the BF (GI2) and virtually heated in a special heat exchanger $(\mathrm{H} 1)$ before reacting in the lower part of the blast furnace, a stream of preheated natural gas (GI4) is also used at the tuyere level. This reduces the amount of coke needed in the burden. In the current study, the flow of natural gas is set to a value ranging from 30 to $50 \mathrm{~kg} /$ (metric ton) of liquid iron as suggested by Peacey and Davenport. ${ }^{[13]}$ The target temperature of this adiabatic reactor is $1800 \mathrm{~K}\left(1527^{\circ} \mathrm{C}\right)$, i.e., the tapping temperature, a temperature at which the slag (GO1) and the liquid pig iron (GO2) are assumed to be in equilibrium. This target temperature is obtained by optimizing the flow and the composition of the hot $\mathrm{O}_{2}$-enriched air input stream (GI3) using MADS. Heat produced by this reactor will be carried out to the upper part of the BF via the hot reducing gas (II1) and the hot virtual coke input stream (VI1).

\section{Thermodynamic simulation of the higher part} of the $B F$

As presented previously, the BF is modeled in the current study using a 5-unit flow sheet, i.e., three equilibrium reactors, one heat exchanger used to quench the exhaust gas and one heat exchanger to heat the cold coke (Figure 4). The higher part of the BF is modeled by four of these thermodynamic units. The first unit simulating the higher part of the BF is an isothermal reactor (R2) operating at a constant temperature of $1200 \mathrm{~K}\left(927^{\circ} \mathrm{C}\right)$. In this reactor, it is supposed that all the iron from the iron ore (oxide impurities are also considered in this charge) coming from the top of the BF (stream GI1) and flowing down to the tuyere is completely reduced to metallic iron. This temperature is considered to be the thermal reserve zone temperature

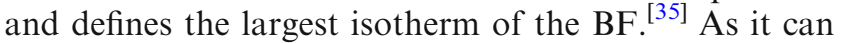
be seen in Figure 4, the gas stream coming from the 


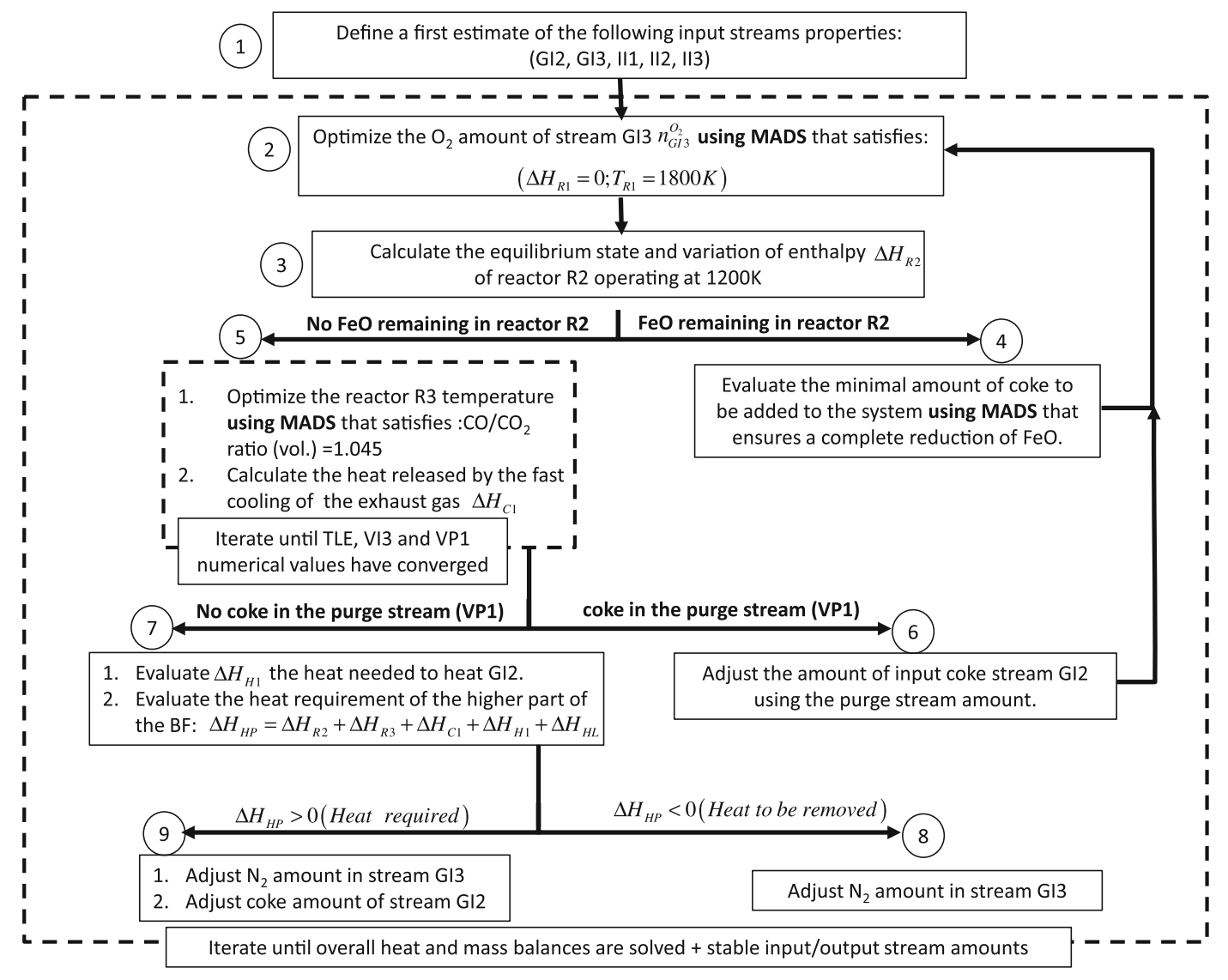

Fig. 5-Schematic representation of the global optimization strategy to solve overall heat and mass balances of the BF.

bottom of the $\mathrm{BF}$ and produced by the combustion of coke with $\mathrm{O}_{2}$-enriched air at high temperature in front of the tuyere enters this reactor at $1800 \mathrm{~K}\left(1527^{\circ} \mathrm{C}\right)$. This combustion gas will provide (1) heat for the direct reduction of $\mathrm{FeO}$ :

$$
\begin{aligned}
& \mathrm{FeO}(\mathrm{s})+\mathrm{C}(\text { coke }) \rightarrow \mathrm{Fe}(\mathrm{s})+\mathrm{CO}(\mathrm{g}) ; \\
& \Delta h^{0}\left[1200 \mathrm{~K}\left(927^{\circ} \mathrm{C}\right)\right]=137.9 \mathrm{~kJ} \mathrm{~mol}^{-1}
\end{aligned}
$$

and (2) the reducing agent, i.e., $\mathrm{CO}(\mathrm{g})$, that will reduce indirectly about 70 pet of the total amount of $\mathrm{FeO}$ $\left(\right.$ Barnaba $\left.^{[36]}\right)$ :

$$
\mathrm{FeO}(\mathrm{s})+\mathrm{CO}(\mathrm{g}) \rightarrow \mathrm{Fe}(\mathrm{s})+\mathrm{CO}_{2}(\mathrm{~g})
$$

Excess carbon needed to complete the reduction process via Reaction [9] comes from the virtual stream VI1 exiting the bottom part of the BF at a temperature of $1800 \mathrm{~K}\left(1527^{\circ} \mathrm{C}\right)$ as seen in Figure 4. Even though this excess coke flow stream is not physically observed in the $\mathrm{BF}$, its magnitude value provides insight about the amount of carbon that ultimately participates in the direct reduction process described by Eq. [9].

It is to be noted that direct reduction given by Eq. [9] is observed experimentally at temperatures greater than $1200 \mathrm{~K}\left(927^{\circ} \mathrm{C}\right)$, i.e., below the thermal reserve zone, as it is a strongly endothermic reaction. However, this observation did not influence the precision of our

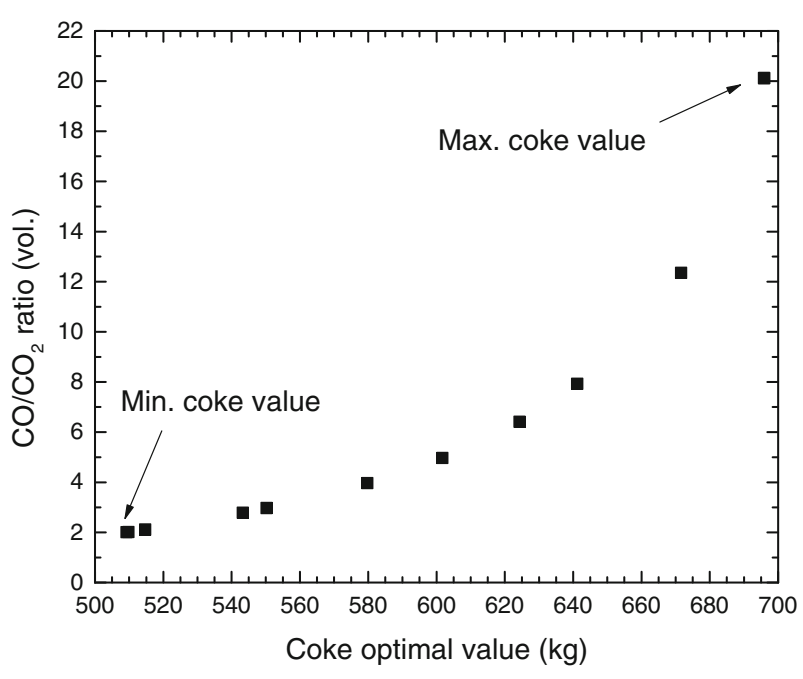

Fig. 6-Evolution of the $\mathrm{CO} / \mathrm{CO}_{2}$ ratio in $\mathrm{GO} 3$ as a function of the coke consumption in the 4-unit process using iron ore \#3 with $n_{\mathrm{GI} 4}^{\mathrm{CH}_{4}}=30 \mathrm{~kg}$.

simulations, as it is not intended to describe the exact temperature profile inside the $\mathrm{BF}$.

The upper quarter of the shaft situated in the higher part of the BF where the temperature of the exhaust gas decreases rapidly because of transfer of heat to cold iron ore, coke and fluxes is modeled using a second equilibrium reactor (third unit defined as $\mathrm{R} 3$ ) and a final heat 
exchanger (fourth-unit defined as $\mathrm{C} 1$ ). The equilibrium reactor is introduced in the simulation to adjust the final equilibrium state reached by the exhaust gas. This unit (R3) is operated at a constant temperature (TLE) optimized by MADS to reproduce typical experimental values of the $\mathrm{CO} / \mathrm{CO}_{2}$ ratio observed in the cooled $\mathrm{BF}$ exhaust gas. ${ }^{[13]}$ Results of preliminary tests using the 4-unit process (Figure 4(a)) performed using a simulation strategy with a similar adjusting equilibrium reactor but operating at the final cooled exhaust gas temperature (for which soot formation is not allowed) reveal that the predicted vol pct of $\mathrm{CO}(\mathrm{g})$ in the final cooled exhaust gas is overestimated in comparison with typical experimental observations (Figure 5). The original simulation strategy also evidently induces a more important carbon solution loss [high $\mathrm{CO}(\mathrm{g})$ concentration] that had to be compensated by an unusually large optimized coke input amount as presented in Figure 6.

For these reasons, it was decided to explore the possibility of performing equilibrium cooling of the exhaust gas to a temperature for which a $\mathrm{CO} / \mathrm{CO}_{2}$ target ratio is reached followed by a fast cooling of the exhaust gas at constant composition (gas quenching) in a virtual heat exchanger. The equilibrium cooling reactor (R3) allows for the formation of soot in the form of coke which is virtually recycled into the isothermal reactor. This virtual recycling loop of coke (V13) induces the need of a virtual purge stream of coke (VP1) to ensure that the simulation process could reach a steady state, i.e., no coke accumulation in the system. During the simulation process, the virtual purge stream amount automatically tunes the amount of coke introduced in the system (GI2) to avoid any coke excess (nil amount in the VP1 stream at the converged solution) at the end of the simulation. Finally, the enthalpy needed to heat the coke from room temperature to $1200 \mathrm{~K}\left(927^{\circ} \mathrm{C}\right)$ is calculated by the heat exchanger $(\mathrm{H} 1)$.

The overall heat balance for this part of the system can be expressed as follows:

$$
\Delta H_{\mathrm{HP}}=\Delta H_{\mathrm{R} 2}+\Delta H_{\mathrm{R} 3}+\Delta H_{\mathrm{C} 1}+\Delta H_{\mathrm{H} 1}+\Delta H_{\mathrm{HL}}
$$

At the thermal balance state, the total variation of enthalpy in the higher part of the reactor $\Delta H_{\mathrm{HP}}$ is equal to 0 . The enthalpy needed to heat coke $\Delta H_{\mathrm{H} 1}$ and to maintain a constant temperature in these reactors $\left(\Delta H_{\mathrm{R} 2}+\Delta H_{\mathrm{R} 3}\right)$ is provided by the hot exhaust gas cooled by a counter-current heat exchange $\Delta H_{\mathrm{C} 1}$. In the current study, it is assumed that there is no heat loss, i.e., $\Delta H_{\mathrm{HL}}=0$.

\section{Phase selection and thermodynamic databases}

All the phases (i.e., stoichiometric compound, liquid and solid solutions, and the gas phase) considered in the equilibrium calculations needed to optimize input streams and other operating parameters of the BF are presented in detail in the documentation of the FactSage software (see FactPS and FToxid databases). ${ }^{[16]}$ This documentation also includes thermodynamic assessments used to parameterize the Gibbs free energy functions. Unless specified in the text, graphite is considered as a metastable phase in all our calculations.
It is to be noted that some special phase selections are used in the current study for some equilibrium reactors presented in Figure 4:

(1) Cementite $\left(\mathrm{Fe}_{3} \mathrm{C}\right)$ was assumed not to form in the isothermal reactor R2. As presented in Section III$\mathrm{B}-4$, an excess of carbon is present in this reactor which saturates the solid iron (in this case the Fe-FCC solid solution) going to the lower part of the blast furnace. Under these equilibrium conditions, cementite (not amorphous carbon) saturates iron and thus defines the maximum solubility of $\mathrm{C}$ in $\mathrm{Fe}$. However, the thermodynamic activity $A_{\mathrm{Fe}_{3} \mathrm{C}}$ of cementite, when it is considered as a metastable phase in the system, is relatively small $(=2)$. The resulting thermodynamic chemical driving force for precipitation of cementite calculated as $-R T \ln \left(A_{\mathrm{Fe}_{3} \mathrm{C}}\right)$ is therefore also small, about $-7 \mathrm{~kJ} \mathrm{~mol}^{-1}$ at $1200 \mathrm{~K}$ $\left(927^{\circ} \mathrm{C}\right)$. According to the nucleation theory, the resulting activation energy for nucleation of cementite will be high, ${ }^{[37]}$ validating our assumption that cementite does not form in this reactor.

(2) Dicalcium silicate $\left(\mathrm{Ca}_{2} \mathrm{SiO}_{4}\right.$ or $\left.2 \mathrm{CaO} \cdot \mathrm{SiO}_{2}\right)$ was assumed not to form in the adiabatic reactor $\mathrm{R} 1$. Like cementite in the isothermal reactor, the activity of dicalcium silicate is small $(=1.3)$ inducing a low thermodynamic chemical driving force for precipitation of $-3.9 \mathrm{~kJ} \mathrm{~mol}^{-1}$. Moreover, preliminary results using the proposed thermodynamic simulation process of the $\mathrm{BF}$ have shown that the total amount of slag going out of the $\mathrm{BF}$ (output stream GO1) in Figure 4 is considerably underestimated compared with experimental evidence when this phase is allowed to precipitate in the reactor.

(3) The chemical composition of the gas phase exiting the virtual equilibrium cooling reactor R3 is assumed to be that of the final exhaust gas defined by the output stream GO3 in Figure 4. This hypothesis implies that the gas is quenched from the temperature TLE of this reactor to the exhaust temperature without the possibility of precipitating any solid phase (e.g., no soot is allowed to form in this region). From a heat-transfer perspective, it is again a reasonable hypothesis as cold iron ore, fluxes, and coke will be heated rapidly by the counter-current exhaust gas flow coming from the thermal reserve zone.

\section{Global optimization strategy of the BF process}

A global optimization strategy was designed in the current study based on the 5-unit thermodynamic process simulation to ensure that the overall mass and heat balances of the system are simultaneously respected at the end of the simulation. A schematic representation of this strategy is presented in Figure 5. For a given iron ore chemical composition and a fixed amount of flux (GI1) and auxiliary fuel (GI4) (which is in this case methane), the simulation process starts (step \#1) with a first rough estimate of the amount of air (GI3) and coke (GI2) to be added to the system. The iterative process starts with the MADS algorithm optimizing the amount of oxygen $n_{\mathrm{GI} 3}^{\mathrm{O}_{2}}$ in the air input stream entering the 
adiabatic reactor at the bottom of the $\mathrm{BF}(\mathrm{R} 1)$ to satisfy the target tapping temperature $T_{\mathrm{R} 1}$ of $1800 \mathrm{~K}\left(1527^{\circ} \mathrm{C}\right)$ (step \#2). The following optimization problem is solved by MADS:

$$
\min _{\substack{\mathrm{O}_{2} \\ n_{\mathrm{Gl}} \in \Re^{n}}}\left(T_{\mathrm{R} 1}\left(n_{\mathrm{Gl3}}^{\mathrm{O}_{2}}\right)-1800\right)^{2}
$$

For the first iteration, the amount of stream II2 has to be estimated and is supposed to consist of the pure oxides $\mathrm{CaO}, \mathrm{MgO}, \mathrm{SiO}_{2}, \mathrm{Al}_{2} \mathrm{O}_{3}$ present in the studied iron ore. The intermediate input stream of solid iron II3 going into the R1 reactor also has to be estimated and is defined as a pure stream containing $1000 \mathrm{~kg}$ (calculation basis) of Fe-FCC. It is assumed in this case that all the $\mathrm{Fe}$-containing minerals are reduced in the isothermal reactor R2. After this first optimization of the R1 reactor, global output streams $\mathrm{GO} 1$ and $\mathrm{GO} 2$ as well as the virtual coke input (VI1) and the reducing gas (II1) streams entering the isothermal reactor $\mathrm{R} 2$ which model the thermal reserve zone are evaluated.

The third step involves the evaluation of the equilibrium state of reactor R2. A binary decision is taken after this equilibrium calculation: if no $\mathrm{FeO}$ remains in II2, then the simulation is continued forward (step \#5); otherwise MADS is used to find a better estimate of the coke amount GI2. In this case, MADS will try to minimize the amount of coke $\Delta n_{\mathrm{GI} 2}^{\mathrm{C}}$ to be added to GI2 to completely reduce $\mathrm{FeO} n_{\mathrm{II} 2}^{\mathrm{FeO}}$ in stream II2 (step \#4):

$$
\begin{array}{r}
\min _{\Delta n_{\mathrm{GI} 2}^{\mathrm{C}} \in \Re^{n}} \Delta n_{\mathrm{GI} 2}^{\mathrm{C}} \\
\text { subject to } \\
n_{\mathrm{II} 2}^{\mathrm{FeO}}=0
\end{array}
$$

When this requirement is met, the simulation continues with the optimization of the higher part of the BF modeled by the isothermal reactor R3. As mentioned previously, the temperature of this reactor where the exhaust gas is cooled with the possibility of precipitation of coke is an optimized variable. Again, MADS is invoked to find the exact temperature at which the target $\mathrm{CO} / \mathrm{CO}_{2}$ ratio of 1.045 in stream II5 is obtained by solving the following problem (step \#5):

$$
\min _{\mathrm{TLE} \in \Re^{n}}\left(\frac{n_{\mathrm{II} 5}^{\mathrm{CO}}(\mathrm{TLE})}{n_{\mathrm{II} 5}^{\mathrm{CO}_{2}}(\mathrm{TLE})}-1.045\right)^{2}
$$

Carbon precipitating in the form of amorphous carbon from this equilibrium cooling reactor is recycled (stream VI3) to the R2 isothermal reactor while the exhaust gas of the II5 stream is quenched to $420 \mathrm{~K}$ $\left(147^{\circ} \mathrm{C}\right)$ using the cooling unit $\mathrm{C} 1$. As the higher part of the $\mathrm{BF}$ involves the presence of a recycling stream (stream VI3), an iterative loop has to be implemented to ensure that the equilibrium temperature of the reactor TLE and the amount of precipitated and recycled coke have reached a converged and stable value. In the course of this iterative loop, an excess of coke in the higher part of the BF rcan occur. This excess carbon coming from reactor R2 will be dumped into the virtual purge VP1. If this situation occurs, then the simulation process will adjust the incoming amount of coke in stream GI2 to ensure that no coke excess in the overall process is present (step \#6).

If no excess carbon is present in stream VP1, the overall heat balance of the higher part of the BF can be evaluated according to Eq. [11] (step \#7). Input streams GI3 and GI2 amounts will finally be adjusted depending on this heat balance: if heat is required in this part of the $\mathrm{BF}$, then the quantity of nitrogen $n_{\mathrm{GI}}^{\mathrm{N}_{2}}$ in stream GI3 will be increased by $\Delta n_{\mathrm{GI}}^{\mathrm{N}_{2}}$ according to the following equation:

$$
\Delta n_{\mathrm{Gl} 3}^{\mathrm{N}_{2}}=\frac{-\Delta H_{\mathrm{HP}}}{\left(\int_{1800 \mathrm{~K}\left(1527^{\circ} \mathrm{C}\right)}^{420 \mathrm{C}\left(147^{\circ} \mathrm{C}\right.} c_{P}\left(N_{2}\right) \mathrm{d} T\right)}
$$

In Eq. [15], $c_{P}\left(\mathrm{~N}_{2}\right)$ represents the heat capacity (by mass) of $N_{2}$ gas. According to Eq. [11], it is assumed in the current study that heat is predominantly transported in the system from the lower part to the upper part by the gas phase via convection, and not by heat conduction or thermal radiation. To heat this extra amount of $\mathrm{N}_{2}$ in the lower part of the BF, a certain amount of coke $\Delta n_{\text {GI2 }}^{\mathrm{C}}$ should also be added to stream GI2 using the enthalpy released by the combustion of incandescent coke in air. This quantity is evaluated as follows:

$$
\Delta n_{\mathrm{GI} 2}^{\mathrm{C}}=\frac{-\Delta n_{\mathrm{GI} 3}^{\mathrm{N}_{2}} \cdot \int_{1350 \mathrm{~K}\left(1077^{\circ} \mathrm{C}\right)}^{1800 \mathrm{C})} c_{P}\left(\mathrm{~N}_{2}\right) \mathrm{d} T}{\Delta h_{\text {combustion }}+\int_{300 \mathrm{~K}\left(27^{\circ} \mathrm{C}\right)}^{1200 \mathrm{~K}\left(27{ }^{\circ} \mathrm{C}\right)} c_{p}(\text { coke }) \mathrm{d} T}
$$

with

$$
\begin{gathered}
\mathrm{C}(\text { coke })_{1200 \mathrm{~K}\left(927^{\circ} \mathrm{C}\right)}+{ }^{1} / 2 \mathrm{O}_{2}(g)_{1350 \mathrm{~K}\left(1077^{\circ} \mathrm{C}\right)} \\
\rightarrow \mathrm{CO}(g)_{1800 \mathrm{~K}\left(1527^{\circ} \mathrm{C}\right)} ; \quad \Delta h_{\text {combustion }}
\end{gathered}
$$

In Eq. [16], $\Delta h_{\text {combustion }}$ represents the variation of enthalpy of combustion (by mass) defined by chemical reaction [17]. According to Eq. [15] and Eq. [16], it is assumed that the excess amount of $\mathrm{CO}$ produced by the combustion of coke to heat $\mathrm{N}_{2}$ in the lower part of the $\mathrm{BF}$ will not provide substantial heat to the higher part of the BF. This assumption does not alter the precision of the converged solution.

In the opposite case, if heat is to be removed from the upper part of the blast furnace, i.e., $\Delta H_{\mathrm{HP}}<0$, then only the amount of $\mathrm{N}_{2}$ in stream GI3 is lowered according to Eq. [15]. In this case, the amount of coke in the system will not be adjusted to ensure that the reducing power ability of the BF is not lowered. One of the main objectives of the simulation process is to evaluate the optimal (in this case also the minimal) amount of coke to be used in the BF that allows for a complete reduction of the iron ore; a small decrease of the coke amount during the iterative process could alter the convergence behavior of the simulation toward this optimal state. This procedure is performed iteratively until both overall heat and mass balances are respected as well as 
until all the input and output stream amounts have converged toward stable values.

\section{THERMODYNAMIC SIMULATION RESULTS}

\section{A. Simulation Results for the 4-Unit Process (No Coke Recirculation)}

The original simulation flow sheet of the BF is presented in Figure 4(a) and is referred to as the 4-unit process. As mentioned previously, it is assumed in this simulation process that the exhaust gas coming from the thermal reserve zone is cooled in equilibrium conditions to the final exhaust gas temperature without the possibility of forming soot. The influence of the first estimate of the coke consumption in the BF on its optimal amount in the reactor is presented in Figure 6. According to this figure, the global optimization strategy proposed in the current study and applied to the original 4-unit process does not automatically minimize the amount of coke used in the BF unless a global optimization strategy managed by MADS to do so is used.

Therefore, an infinite no. of solutions exist between the lowest amount of coke to be used to reduce completely all the iron ore and the maximum amount of coke above which an excess of unreacted coke will be present in the BF. This implies that the simulation performed with the original 4-unit approach is sensitive to the initial guess: an unnecessary large amount of coke in the reactor does not therefore result in a coke excess in the BF, as it can be burnt by air and still solves the overall mass and heat balances of the system. In this case, the $\mathrm{CO} / \mathrm{CO}_{2}$ ratio of the exhaust gas is the perfect indication of the optimum selected input amounts, a high coke injection inducing a high $\mathrm{CO} / \mathrm{CO}_{2}$ ratio in the exhaust gas. If compared with industrial $\mathrm{CO} / \mathrm{CO}_{2}$ ratios reported by Peacey and Davenport ${ }^{[13]}$ for $4-\mathrm{BFs}$ which are between 1 and 1.4, the 4-unit process overestimates the $\mathrm{CO} / \mathrm{CO}_{2}$ ratio even for the minimal amount of coke to be used to complete the reduction of the iron ore. These results motivated the construction of the 5-unit process which is used to generate all the other results presented in the current study.

\section{B. Effect of the Carbon State on the Optimized Input and Output Streams Variables}

The parameterization of the Gibbs free energy function of coke presented in Appendix 1 of the current study was done to demonstrate the influence of the selected carbon state, i.e., graphite or metallurgical coke, on the BF optimized process parameters. The first effect of the carbon state on the thermodynamic simulations is related to the overall heat balance of the system. The variation of the enthalpy to perform the graphite-toamorphous phase transition is $13.6 \mathrm{~kJ} \mathrm{~mol}^{-1}$ under standard conditions and goes up to $15.1 \mathrm{~kJ} \mathrm{~mol}^{-1}$ at $1800 \mathrm{~K}\left(1527^{\circ} \mathrm{C}\right)$. As a direct consequence, the combustion of graphite at the tuyere level in the BF is less
Table III. Optimized BF Process Parameters Comparison Between Injected Coke and Graphite for the Reduction of Iron Ore \#1 with $n_{\mathbf{G I} 4}^{\mathbf{C H}_{4}}=30 \mathrm{~kg}$

\begin{tabular}{lll}
\hline BF Process Parameter & Coke & Graphite \\
\hline Injected carbon amount GI2 (kg) & 458 & 456 \\
Carbon in stream VI1 & 137 & 113 \\
Blast & & \\
$\mathrm{N}_{2}(\mathrm{~kg})$ & 1109 & 1071 \\
$\mathrm{O}_{2}(\mathrm{~kg})$ & 383 & 418 \\
$\mathrm{TLE}_{\text {of unit }}$ R $(\mathrm{K})$ & 849 & 913 \\
Exhaust gas composition (vol pct) & & \\
$\mathrm{N}_{2}$ & 51.1 & 49.4 \\
$\mathrm{CO}$ & 22.7 & 23.4 \\
$\mathrm{CO}$ & 21.7 & 22.4 \\
$\mathrm{H}_{2} \mathrm{O}$ & 1.0 & 1.5 \\
$\mathrm{H}_{2}$ & 3.2 & 3.3 \\
$\mathrm{CH}$ & 0.3 & $293 \mathrm{ppm}$ \\
$\mathrm{Pig}$ iron composition (wt pct) & & \\
$\mathrm{C}$ & 5.9 & 4.8 \\
$\mathrm{Si}$ & 1.6 & 1.3 \\
$\mathrm{Al}$ & $1272 \mathrm{ppm}$ & $1225 \mathrm{ppm}$ \\
\hline
\end{tabular}

exothermic, representing about 89 pct of the value presented in Eq. [8]. As presented in Table III, this observation does not imply that more graphite is needed in the $\mathrm{BF}$, as its minimal amount is set by the complete reduction of the iron ore and the specific $\mathrm{CO} / \mathrm{CO}_{2}$ requirements rather than by the heat balance. However, the amount of $\mathrm{O}_{2}$ in the blast is lower when coke is used (the combustion in this case is more exothermic) which means that more $\mathrm{FeO}$ is directly reduced by coke than for graphite. Heat needed to perform the direct reduction is provided by $\mathrm{N}_{2}$ as can be seen in Table III.

The second effect of the carbon state on the simulation results is related to the exhaust gas chemical composition. As provided in Table III, the temperature of last equilibrium (TLE) in unit R3 is 64 deg lower when coke is used for reasons presented in Section IV-E. As a direct consequence, the chemical composition of the equilibrium exhaust gas coming out of unit R3 is also dependent on the carbon state considered in the BF. This simulation parameter can be critical when predicting precisely greenhouse gas emissions such as $\mathrm{CO}_{2}$ and $\mathrm{CH}_{4}$ as highlighted by Table III.

The last effect of the carbon state, on the thermodynamic simulation results, is the modification of carbon solubility in the liquid pig iron. Coke is less thermodynamically stable than graphite. Carbon saturation in the liquid pig iron is therefore higher when coke saturates the metallic liquid solution in comparison with graphite.

\section{Effect of the Pig Iron/Slag/Coke Equilibrium Temperature on the Coke Consumption, the Presence of Si in Liquid Fe and on the Slag Basicity}

In this section, we present the effect of the final equilibrium temperature in the $\mathrm{LP}$ of the $\mathrm{BF}$ reactor (tapping temperature) on the chemical composition of liquid pig iron and on the slag basicity. Figure 7(a) shows that the coke consumption increases almost linearly as the temperature of the LP of the BF is increased. In this figure, 


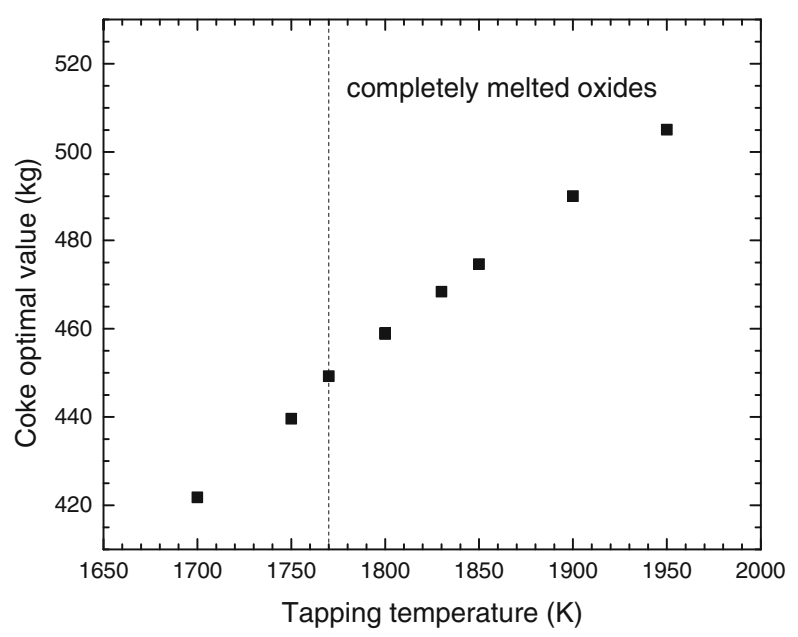

(a)

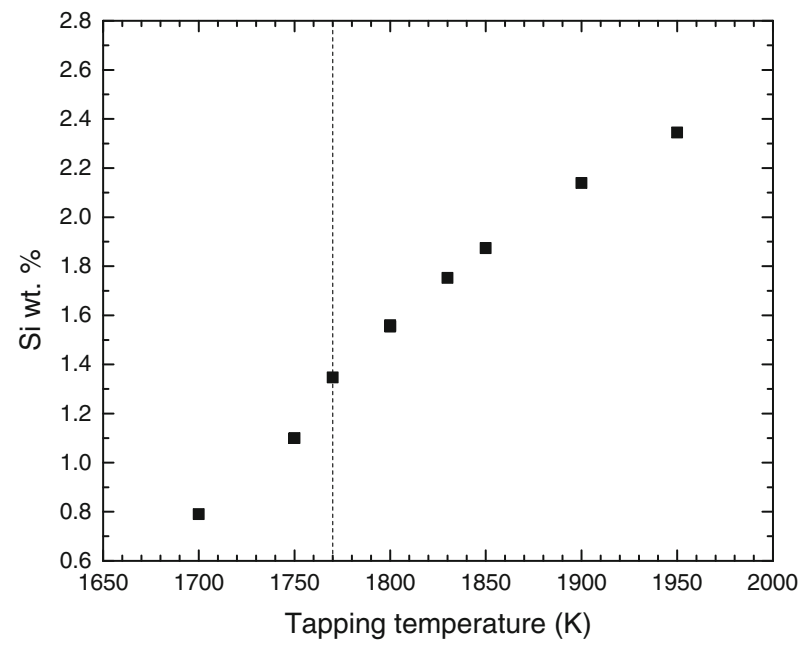

(b)

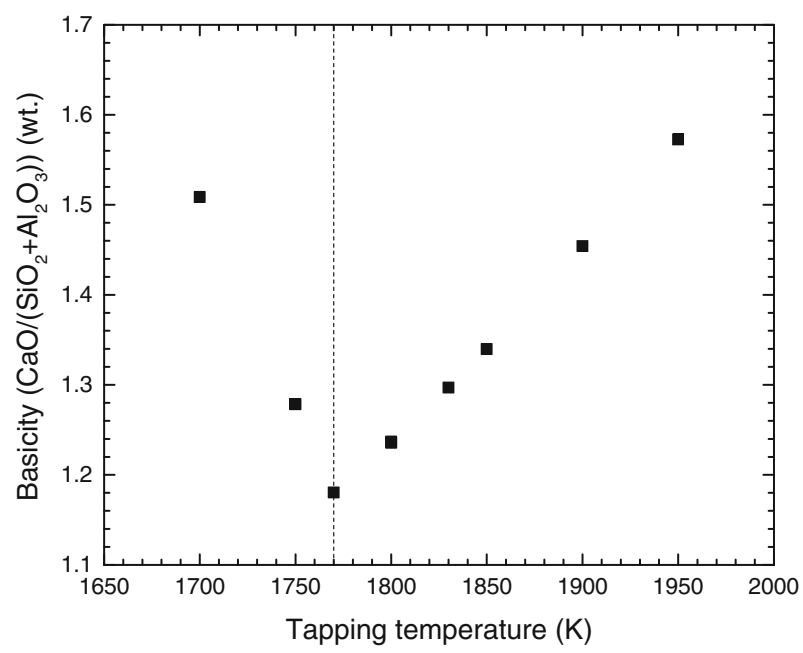

(c)

Fig. 7-Evolution of ( $a$ ) coke optimal value, $(b) \mathrm{Si}$ (wt pct) dissolved in the liquid pig iron, $(c)$ resulting slag basicity as a function of the tapping temperature when reducing iron ore id \#1 using metallurgical coke and with $n_{\mathrm{GI} 4}^{\mathrm{CH}_{4}}=30 \mathrm{~kg}$. the minimal LP temperature needed to melt completely all the oxide impurities is presented as a dashed line and occurs at around $1770 \mathrm{~K}\left(1497{ }^{\circ} \mathrm{C}\right)$ for the iron ore considered in these calculations. As is well known, reduction of $\mathrm{SiO}_{2}$ is thermodynamically favored as temperature is increased, which explains the increases in the equilibrium silicon content as a function of the LP temperature presented in Figure 7(b). Finally, the evolution of the basicity of the (bottom or hearth) slag defined in this case as the $\mathrm{CaO} /\left(\mathrm{SiO}_{2}+\mathrm{Al}_{2} \mathrm{O}_{3}\right)$ ratio (by weight) is presented in Figure 7(c). To operate the $\mathrm{BF}$ for an optimal slag basicity of around 1.2, the tapping temperature for the studied iron ore should be around $1790 \mathrm{~K}$ $\left(1517^{\circ} \mathrm{C}\right)$, which is close to the recommended general tapping temperature. ${ }^{[13]}$

\section{Effect of the Iron Ore Chemical Composition on Operating Parameters and Output Streams of the BF}

In this section, several iron ore compositions have been tested in the 5-unit thermodynamic simulation process. Results of these simulations are presented in Table IV and can be compared with the reference data provided by Peacey and Davenport. ${ }^{[13]}$ In this table, predicted values are presented in bold characters. It is to be noted that Peacey and Davenport ${ }^{[13]}$ did not provide the exact chemical composition of the iron ore considered for their proposed reference data, which limits the evaluation of the precision of the thermodynamic simulations performed in the current study. Apart from the amount of $\mathrm{C}$ in the liquid pig iron, which is slightly overestimated when compared with reference data, there is excellent agreement between predicted and reference data. In our simulations, the amount of carbon in the liquid pig iron is imposed by coke saturation of the melt. To obtain a saturation of about 5 pct, graphite would have to be considered in the calculations. Another thermodynamic justification that could explain this small discrepancy is the extrapolation of the Gibbs free energy function of coke parameterized in the current study to high temperatures where no experimental data are reported in the literature. In this case, the thermodynamic stability of coke, compared with graphite, would be underestimated. It also appears that the predicted $\mathrm{Si}$ content in the resulting pig iron in complete equilibrium with the slag phase is slightly overestimated when compared with other conventional BF data. ${ }^{[38]}$ This is presumably caused by kinetics limitations of the reduction of $\mathrm{SiO}_{2}$ in the LP of the BF. ${ }^{[38]}$ In such a perspective, models of reaction rates should be added to our model of the BF in future refinements of our proposed approach.

E. Influence of the Selected Carbon Gibbs Free Energy Function and Nitrogen Partial Pressure on the Boudouard Reaction Equilibrium at Low Temperature on the Phase Equilibria of the $B F$

Figure 8 presents the $\left[\log _{10}\left(\mathrm{PO}_{2}\right)\right.$ vs $\left.\mathrm{T}\right]$ predominance phase diagram of the $\mathrm{Fe}-\mathrm{O}$ system obtained from 
Table IV. BF Input/Output Parameters for Different Iron Ore Using Coke Compared with Reference Data of Peacey and Davenport $^{[13]}$ (Calculation Basis: $1000 \mathrm{~kg}$ of Liquid Fe)

\begin{tabular}{|c|c|c|c|c|c|c|}
\hline BF Parameters & Unit & Iron Ore \#1 & Iron Ore \#2 & Iron Ore \#3 & Iron Ore \#4 & Ref. [13] \\
\hline $\begin{array}{l}\text { Iron ore total amount } \\
\quad \text { (flux and impurities included) }\end{array}$ & $\mathrm{kg}$ & 1740 & 1585 & 1677 & 1536 & $1750^{*}$ \\
\hline Coke input amount & kg & 442 & 427 & 421 & 417 & 450 \\
\hline Blast temperature & $\mathrm{K}$ & 1350 & 1350 & 1350 & 1350 & 1350 \\
\hline Blast pressure & bar & 2 & 2 & 2 & 2 & 2 to 3.4 \\
\hline \multirow{2}{*}{$\mathbf{N}_{2}$ in blast } & kg & 1020 & 1100 & 923 & 1161 & 1027 \\
\hline & vol pet (STP) & 75.5 & 78.3 & 74.2 & 80 & 78.9 \\
\hline \multirow[t]{2}{*}{$\mathrm{O}_{2}$ in blast } & kg & 378 & 348 & 366 & 330 & 313 \\
\hline & vol pet (STP) & 25.5 & 21.7 & 25.8 & 20 & 21.1 \\
\hline Tapping $T$ & $\mathrm{~K}$ & 1800 & 1800 & 1800 & 1800 & 1800 \\
\hline $\mathrm{CaO} /\left(\mathrm{SiO}_{2}+\mathrm{Al}_{2} \mathrm{O}_{3}\right)$ ratio in the slag & - & 1.1 & 1.2 & 1.5 & 1.7 & 1.1 to 1.2 \\
\hline Slag total amount & kg & 286 & 139 & 247 & 100 & 300 \\
\hline Auxiliary $\mathrm{CH}_{4}$ & $\mathrm{~kg}$ & 50 & 50 & 50 & 50 & 50 \\
\hline Top-gas temperature & K & 420 & 420 & 420 & 420 & 420 \\
\hline Top-gas pressure & bar & 1 & 1 & 1 & 1 & 0.3 to 2.2 \\
\hline Top-gas amount & kg & 2264 & 2294 & 2109 & 2320 & 2300 \\
\hline \multicolumn{7}{|l|}{ Top-gas analysis } \\
\hline pet $\mathrm{N}_{2}$ & vol pet & 48 & 51 & 47 & 53 & 49 \\
\hline pet $\mathrm{CO}$ & vol pet & 23 & 21 & 23 & 21 & 23 \\
\hline pct $\mathrm{CO}_{2}$ & vol pet & 22 & 20 & 22 & 20 & 22 \\
\hline pet $\mathrm{H}_{2}$ & vol pet & 5 & 5 & 5 & 5 & 3 \\
\hline pct $\mathrm{H}_{2} \mathrm{O}$ & vol pet & 2 & 2 & 2 & 1 & 3 \\
\hline pet $\mathrm{CH}_{4}$ & vol pet & $\mathbf{0}$ & 1 & 1 & 1 & - \\
\hline \multicolumn{7}{|l|}{ Pig iron chemical compo. } \\
\hline $\mathrm{C}$ & wt pet & 6.2 & 6.4 & 6.1 & 6.6 & 4 to 5 \\
\hline $\mathrm{Si}$ & wt pet & 1.0 & 0.6 & 1.3 & 0.3 & 0.3 to 1 \\
\hline
\end{tabular}

* Total amount of iron ore $(1600 \mathrm{~kg})$ and $\mathrm{CaO}$ flux $(150 \mathrm{~kg})$.

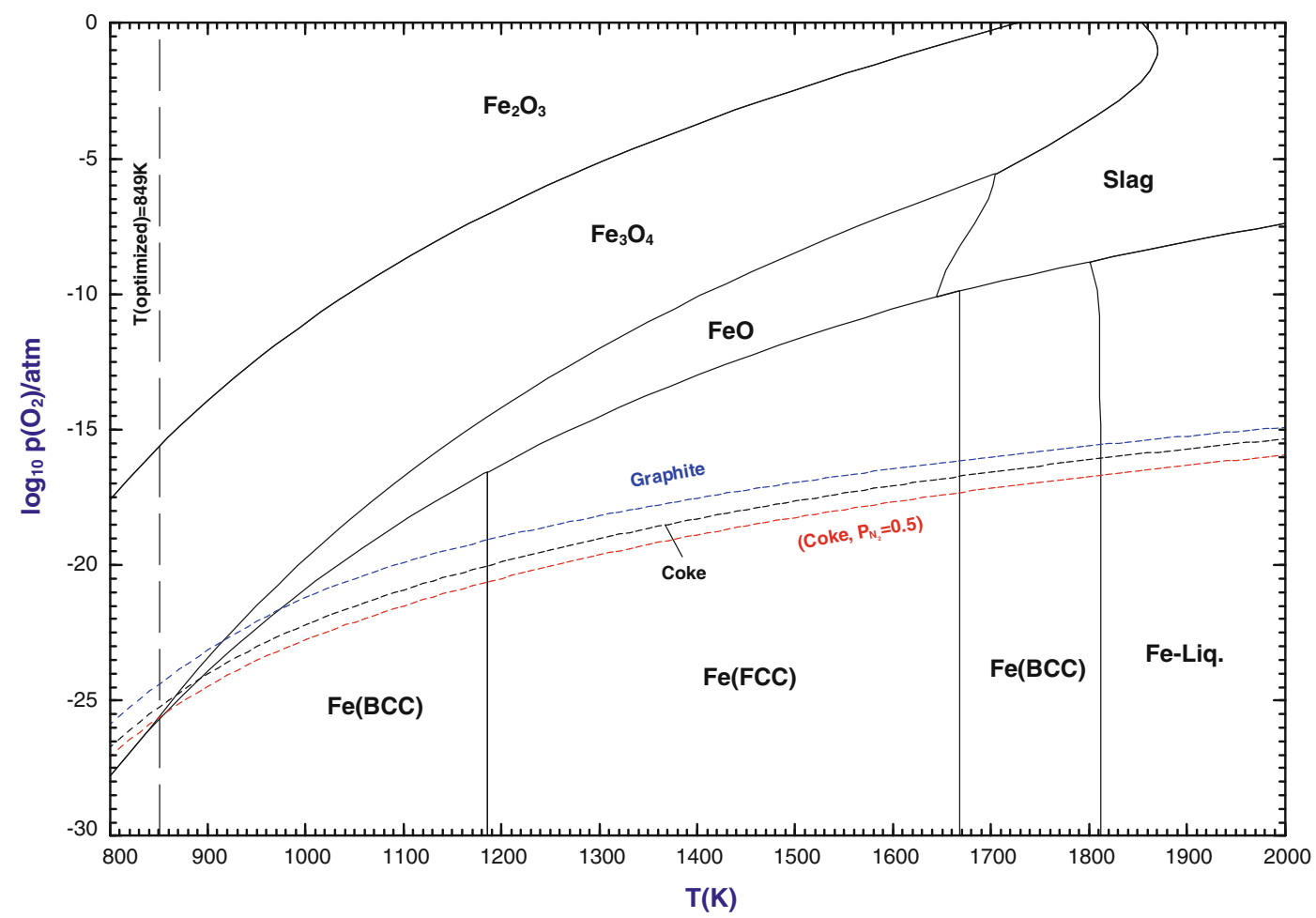

Fig. 8 - $\left(\mathrm{PO}_{2}\right.$ vs $\left.T\right)$ predominance phase diagram of the Fe-O system. The calculations are based on a total pressure of $1 \mathrm{~atm}$. 
thermodynamic calculations performed with FactSage based on a total pressure of $1 \mathrm{~atm}$. The dashed lines represent the equilibrium partial pressure of $\mathrm{O}_{2}$ imposed by the Boudouard reaction (Eq. [2]) in a system having an excess of carbon.

As is well established, complete reduction of $\mathrm{Fe}_{2} \mathrm{O}_{3}$ to form metallic iron is thermodynamically favored at temperatures greater than $970 \mathrm{~K}\left(697^{\circ} \mathrm{C}\right)$ when the Boudouard reaction constrains the reducing conditions in the system and if the Gibbs free energy function of graphite is considered. For metallurgical coke, which is less thermodynamically stable than graphite, the minimum theoretical temperature needed to obtain metallic iron is $890 \mathrm{~K}\left(617^{\circ} \mathrm{C}\right)$. Finally, if a nitrogen partial pressure is imposed on the system, as in conventional BFs blowing enriched air (in this case $\mathrm{PN}_{2}=0.5$ in the upper part of the $\mathrm{BF}$ ), the minimum temperature for complete reduction to metallic iron decreases to $855 \mathrm{~K}$ $\left(582^{\circ} \mathrm{C}\right)$. This temperature is close to the optimized temperature obtained from our simulations if an assumed $\mathrm{CO} / \mathrm{CO}_{2}$ of 1.045 is to be reached before the exhaust gas is quenched. Moreover, if one assumes that the last equilibrium to be reached in the BF before the exhaust gas leaves the BF ris:

$$
\mathrm{FeO}(s)+\mathrm{Fe}_{3} \mathrm{O}_{4}(s)+\text { Coke }+ \text { exhaust gas }
$$

then the required temperature for this equilibrium phase assemblage would be exactly the optimized temperature of the exhaust gas calculated from our simulations. The Gibbs phase rule defining the no. of degree of freedom $F$ as a function of the no. of distinct chemical species $C$ and no. of stable phases at equilibrium $P$, i.e., $F=C-P+2$, confirms this observation. For the basic BF chemical system defined by $\mathrm{N}, \mathrm{C}, \mathrm{Fe}, \mathrm{O}(C=4)$, the phase assemblage provided in Eq. [18] with $P=4$ is completely defined $(F=0)$ if the total pressure and the nitrogen activity in the system are imposed in the BF. At this temperature, the resulting $\mathrm{CO} / \mathrm{CO}_{2}$ ratio determined by this phase assemblage is equal to 1.045 .

\section{CONCLUSIONS AND PERSPECTIVES}

In the current study, the conventional BF has been modeled using a 5-unit simulation flow sheet using classical thermodynamic calculations combined with a direct search algorithm called MADS. The complexity related to the formation and chemical evolution of the slag phase has demonstrated the necessity of simplifying this complex industrial process to a 5-unit countercurrent reactor. To improve the thermodynamic description of this system, the Gibbs free energy of metallurgical coke has been parameterized and validated using available experimental data. Several results obtained with this proposed simulation strategy were compared with the literature data and have demonstrated its accuracy and high predictive power.

This newly elaborated thermodynamic approach for simulating BF can now be applied to study quantitatively other important phenomena occurring in the BF, such as the accumulation of alkali elements and $\mathrm{Zn}$ and subsequent degradation of the BF refractory materials. ${ }^{[39]}$ Another example is liquid metal quality control when sulfur is present. ${ }^{[40]}$ In future study, this simulation strategy will also be used to explore new optimal operating conditions of the $\mathrm{BF}$ to meet new important industrial constraints such as reduction of gaseous emissions and improved energy efficiency of the process. Finally, the MADS algorithm will be used to perform complex optimizations that simultaneously target liquidus temperature and slag viscosity to improve the operation of the BF.

\section{ACKNOWLEDGMENT}

We would like to thank Professor Patrice Chartrand and Dr. James Sangster for their constructive criticisms of the current study.

\section{APPENDIX 1}

There are two specific amorphous forms of carbon: the diamond-like amorphous carbon and the graphitelike amorphous carbon. ${ }^{[41]}$ The diamond-like amorphous carbon is made of distorted $\mathrm{sp}^{3}$ bonds whereas the graphite-like amorphous carbon is characterized by a high percentage $(>80 \mathrm{pct})$ of $\mathrm{sp}^{2}$ bonds. The ratio of fourfold diamond-like bonds to threefold graphite-like bonds $\left(\mathrm{sp}^{3} / \mathrm{sp}^{2}\right)$ determines the structure.

In fact in amorphous carbon the chemical bonds among atoms are a mixture of $\mathrm{sp}^{2}$ and $\mathrm{sp}^{3}$ hybridized bonds with a high concentration of dangling bonds. Because amorphous carbon is thermodynamically in a metastable state and the ratio of $\mathrm{sp}^{2}$ and $\mathrm{sp}^{3}$ hybridized bonds are variable, physical properties of amorphous carbon vary greatly depending on formation methods and conditions. In the current study, we do not take into account the specificity of the nature of the binding within the solid in the formulation of the Gibbs free energy. We assume that coke is energetically defined by the Gibbs free energy of an amorphous carbon with purely covalent binding.

The Gibbs free energy difference due to amorphization of graphite can be written as follows:

$$
\begin{aligned}
\Delta g^{g . \rightarrow a} \cdot(T) & =\Delta h^{g \cdot \rightarrow a}\left(T_{0}\right)+\int_{T_{0}}^{T} \Delta c_{P}^{g \cdot \rightarrow a}\left(T^{\prime}\right) \mathrm{d} T^{\prime} \\
& -T \Delta s^{g \cdot \rightarrow a}\left(T_{0}\right)-T \int_{T_{0}}^{T} \frac{\Delta c_{P}^{g . \rightarrow a \cdot}(T \prime)}{T \prime} \mathrm{d} T^{\prime}
\end{aligned}
$$

with $T_{0}=298 \mathrm{~K}\left(25^{\circ} \mathrm{C}\right), \Delta h^{g . \rightarrow a}, \Delta s^{g . \rightarrow a}$. and $\Delta c_{P}^{g . \rightarrow a}$. are, respectively, the molar enthalpy, molar entropy and molar heat capacity change due to amorphization of graphite. In this assessment, $\Delta s^{g . \rightarrow a} \cdot\left(T_{0}\right)$ is taken to be $0.2 R$ which is the upper theoretical limit value of the excess ideal configurational entropy due to lattice disorder in the amorphous phase determined by Spaepen ${ }^{[42]}$ 
and based on random network models. The $\Delta c_{p}^{g . \rightarrow a}$. expression used in the current study is set to a constant value (no temperature dependence) of similar amplitude as for silicon $\left(0.96 \mathrm{~J} \mathrm{~mol}^{-1} \mathrm{~K}^{-1}\right)$ and germanium $\left(0.62 \mathrm{~J} \mathrm{~mol}^{-1} \mathrm{~K}^{-1}\right)$ at room temperature evaluated by Donovan et al., ${ }^{[43]}$ i.e., assuming $\Delta c_{P}^{g . \rightarrow a .}=$ $1 \mathrm{~J} \mathrm{~mol}^{-1} \mathrm{~K}^{-1}$.

The standard molar enthalpy of amorphization of graphite $\Delta h^{g . \rightarrow a .}\left[298 \mathrm{~K}\left(25^{\circ} \mathrm{C}\right)\right]$ can be estimated using the following thermodynamic path:

\begin{tabular}{|c|c|c|c|}
\hline $\begin{array}{l}\text { graphite } \\
\Delta h_{1} \downarrow\end{array}$ & 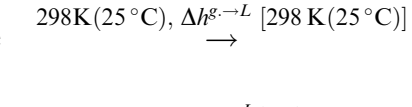 & $\begin{array}{l}\text { liquid } \\
\Delta h_{2} \uparrow\end{array}$ & [A2] \\
\hline $\begin{array}{l}\text { graphite } \\
+\end{array}$ & $\begin{array}{r}T_{m}, \Delta h^{g . \rightarrow L} \\
\longrightarrow\end{array}$ & liquid & \\
\hline $\begin{array}{l}\text { liquid } \\
\Delta h_{3} \downarrow\end{array}$ & $\begin{aligned} 298 \mathrm{~K}\left(25^{\circ} \mathrm{C}\right), \Delta h^{L \rightarrow a .} & {\left[298 \mathrm{~K}\left(25^{\circ} \mathrm{C}\right),\right] }\end{aligned}$ & $\begin{array}{l}\text { amorphous } \\
\Delta h_{4} \uparrow\end{array}$ & [A3] \\
\hline liquid & $\begin{array}{c}T_{g}, \Delta h^{L \rightarrow a .}\left(T_{g}\right) \\
\longrightarrow\end{array}$ & amorphous & \\
\hline
\end{tabular}

$$
\begin{aligned}
& \Delta h^{g . \rightarrow a \cdot}\left[298 \mathrm{~K}\left(25^{\circ} \mathrm{C}\right)\right]=\Delta h^{g . \rightarrow L}\left[298 \mathrm{~K}\left(25^{\circ} \mathrm{C}\right)\right] \\
& +\Delta h^{L \rightarrow a \cdot}\left[298 \mathrm{~K}\left(25^{\circ} \mathrm{C}\right)\right]=\Delta h_{1}+\Delta h^{g . \rightarrow L}\left(T_{m}\right) \\
& +\Delta h_{2}+\Delta h_{3}+\Delta h^{L \rightarrow a \cdot}\left(T_{g}\right)+\Delta h_{4}
\end{aligned}
$$

with:

$$
\begin{gathered}
\Delta h_{1}=\int_{\left[298 \mathrm{~K}\left(25^{\circ} \mathrm{C}\right)\right]}^{T_{m}} c_{P}(\text { graphite }) \mathrm{d} T \\
\Delta h_{2}=\int_{T_{m}} c_{P}(\text { liquid }) \mathrm{d} T \\
\Delta h_{3}=\int_{\left[298 \mathrm{~K}\left(25^{\circ} \mathrm{C}\right)\right]}^{T_{g}} c_{P}(\text { liquid }) \mathrm{d} T \\
\Delta h_{4}=\int_{T_{g}}^{T_{g}} c_{P}(\text { amorphous }) \mathrm{d} T
\end{gathered}
$$

At $T_{g}$, the Clausius-Clapeyron rule can be applied:

$$
\Delta h^{L \rightarrow a .}\left(T_{g}\right)=T_{g} \cdot \Delta s^{L \rightarrow a .}\left(T_{g}\right)
$$

or equivalently:

$$
\Delta h^{L \rightarrow a \cdot}\left(T_{g}\right)=T_{g} \cdot\left[\Delta s^{L \rightarrow g \cdot}\left(T_{g}\right)+\Delta s^{g . \rightarrow a \cdot}\left(T_{g}\right)\right]
$$

One can assume that

$$
\Delta s^{L \rightarrow g \cdot}\left(T_{g}\right)=\Delta s^{L \rightarrow g \cdot}\left(T_{m}\right)
$$

At the melting temperature $T_{m}$ of graphite, the Clausius-Clapeyron rule can be applied again:

$$
\Delta s^{L \rightarrow g .}\left(T_{m}\right)=\frac{\Delta h^{L \rightarrow g \cdot}\left(T_{m}\right)}{T_{m}}=\frac{-\Delta h^{g . \rightarrow L}\left(T_{m}\right)}{T_{m}}
$$

The value of $\Delta s^{g . \rightarrow a \cdot}\left(T_{g}\right)$ in Eq. [A10] can be evaluated from the theoretical molar excess configurational entropy of $0.2 R$ determined by Spaesen ${ }^{[42]}$ and using the $\Delta c_{p}^{g . \rightarrow a}$. expression defined previously. This results in the following equation:

$$
\Delta s^{g . \rightarrow a .}\left(T_{g}\right)=0.2 R+\int_{298}^{T_{\mathrm{K}\left(25^{\circ} \mathrm{C}\right)}^{T_{g}}} \frac{\Delta c_{P}^{g . \rightarrow a .}}{T} \mathrm{~d} T
$$

According to the Kauzmann-Beaman rule, a linear relationship exists between $T_{m}$ and $T_{g}$, i.e., $T_{g}=\omega T_{m}$ with $\omega=0.74$ to 0.76 for purely covalent-type bonding. ${ }^{[44]}$ Finally Eq. [A4] can be re-written using the previous equations as follows:

$$
\begin{aligned}
& \Delta h^{g . \rightarrow a}\left[298 \mathrm{~K}\left(25^{\circ} \mathrm{C}\right)\right]=\int_{298 \mathrm{~K}\left(25^{\circ} \mathrm{C}\right)}^{T_{m}} c_{P}(\text { graphite }) \mathrm{d} T \\
& \left.\quad+\int_{T_{m}}^{\omega T_{m}} c_{P}(\text { liquid }) \mathrm{d} T+\int_{\omega T_{m}}^{298 \mathrm{~K}\left(25^{\circ} \mathrm{C}\right)} c_{P} \text { (amorphous }\right) \mathrm{d} T \\
& +\Delta h^{g . \rightarrow L}\left(T_{m}\right)+\omega T_{m} \\
& {\left[\frac{-\Delta h^{g . \rightarrow L}\left(T_{m}\right)}{T_{m}}+0.2 R+\int_{298 \mathrm{~K}\left(25^{\circ} \mathrm{C}\right)}^{\omega T_{m}} \frac{\Delta c_{P}^{g . \rightarrow a .}}{T} \mathrm{~d} T\right]}
\end{aligned}
$$

According to Eq. [A14], three thermodynamic properties associated to the liquid phase are required to estimate $\Delta h^{g . \rightarrow a .}\left[298 \mathrm{~K}\left(25^{\circ} \mathrm{C}\right)\right]$. These properties are $T_{m}, \Delta h^{g . \rightarrow L}\left(T_{m}\right)$, and $c_{p}$ (liquid).

Thermodynamic data for liquid carbon $^{[45]}$ are scattered due its metastability at standard pressure (i.e., $\left.10^{5} \mathrm{~Pa}\right)$. In fact graphite sublimates at $3915 \mathrm{~K}$ $\left(3642{ }^{\circ} \mathrm{C}\right)$ under standard pressure. According to the literature review of Savvatimskiy, ${ }^{[45]}$ the melting temperature of graphite lies between $4000 \mathrm{~K}$ and $5000 \mathrm{~K}$ $\left(3727^{\circ} \mathrm{C}\right.$ and $\left.4727^{\circ} \mathrm{C}\right)$. The recommended melting temperature proposed by Dinsdale ${ }^{[46]}$ as well as the recent assessed value of Savvatimskiy ${ }^{[45]}$ is $4800 \mathrm{~K}$ $\left(4527^{\circ} \mathrm{C}\right)$, with an estimated error of $100 \mathrm{deg}$ according to the latter author. This temperature is in agreement with the most recent investigation of Kerley and Chhabildas, ${ }^{[47]}$ which states that the melting temperature of graphite is above $4600 \mathrm{~K}\left(4327^{\circ} \mathrm{C}\right)$. In the current study, we have considered $T_{m}=4800 \mathrm{~K}$ $\left(4527^{\circ} \mathrm{C}\right)$.

The molar heat of fusion of graphite $\Delta h^{g \cdot \rightarrow L}\left(T_{m}\right)$ is more difficult to assess. Based on the optimization of the 
unary $(\mathrm{P}-\mathrm{T})$ phase diagram of the carbon, Bundy ${ }^{[48]}$ recommended a value of $105 \mathrm{~kJ} \mathrm{~mol}^{-1}$. This value is in agreement with the range recommended by Pottlacher et al. ${ }^{[49]}\left(96\right.$ to $\left.108 \mathrm{~kJ} \mathrm{~mol}^{-1}\right)$. The latest assessment of Savvatimskiy ${ }^{[45]}$ suggests a value of $120 \mathrm{~kJ} \mathrm{~mol}^{-1}$. In the current study, we considered an average value of $110 \mathrm{~kJ} \mathrm{~mol}^{-1}$.

According to the literature review of Savvatimsky, ${ }^{[45]}$ the molar heat capacity of liquid $c_{\mathrm{p}}$ (liquid) carbon ranges between 38.4 and $49.2 \mathrm{~J} \mathrm{~mol}^{-1} \mathrm{~K}^{-1}$. A value of $c_{p}($ liquid $)=49.2 \mathrm{~J} \mathrm{~mol}^{-1} \mathrm{~K}^{-1}$ was used in the current study as suggested by Savvatimsky. ${ }^{[45]}$

Using all these thermodynamic properties, a value of $\Delta h^{g . \rightarrow a .}\left[298 \mathrm{~K}\left(25^{\circ} \mathrm{C}\right)\right]=13.6 \pm 2.5 \mathrm{~kJ} \mathrm{~mol}^{-1}$ is estimated which is exactly within the range of experimentally reported values. ${ }^{[25]}$ This estimated molar enthalpy of amorphization of graphite also compares well with the experimental data for amorphous silicon $11.9 \mathrm{~kJ}$ $\mathrm{mol}^{-1[50]}$ and amorphous germanium $11.6 \mathrm{~kJ} \mathrm{~mol}^{-1}$. ${ }^{[43]}$ It also agrees with the estimation made by de Bokx et al. ${ }^{[51]}$ i.e., that $\Delta h^{g . \rightarrow a .}\left[298 \mathrm{~K}\left(25^{\circ} \mathrm{C}\right)\right]$ should not exceed $15 \mathrm{~kJ} \mathrm{~mol}^{-1}$. A slightly higher value of $\Delta h^{g . \rightarrow a} .\left[298 \mathrm{~K}\left(25^{\circ} \mathrm{C}\right)\right]=19.2 \mathrm{~kJ} \mathrm{~mol}^{-1}$ attributed to the strong bonding nature of carbon has been reported by Konno and Sinclair. ${ }^{[52]}$ This value however contradicts the constraint of de Bokx et al. ${ }^{[51]}$ Moreover, this value was obtained experimentally by DSC on a C/Co thin film, where size and chemical effects between $\mathrm{Co}$ and $\mathrm{C}$ affect the estimation.

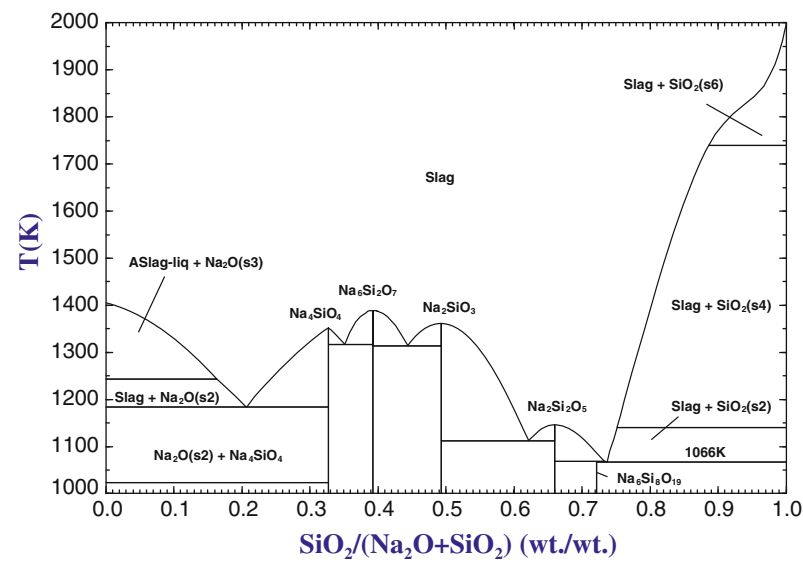

Fig. A1-Pseudo-binary phase diagram of the $\mathrm{Na}_{2} \mathrm{O}-\mathrm{SiO}_{2}$ system (no gas phase considered) calculated by FactSage using the FToxid database. ${ }^{[16]}$
The final theoretical Gibbs free energy function predicted from this procedure is compared with the experimental data reported by Jacob and Seethar$\operatorname{aman}^{[25]}$ in Figure 1.

\section{APPENDIX 2}

See Figures A1, A2, A3 and A4.

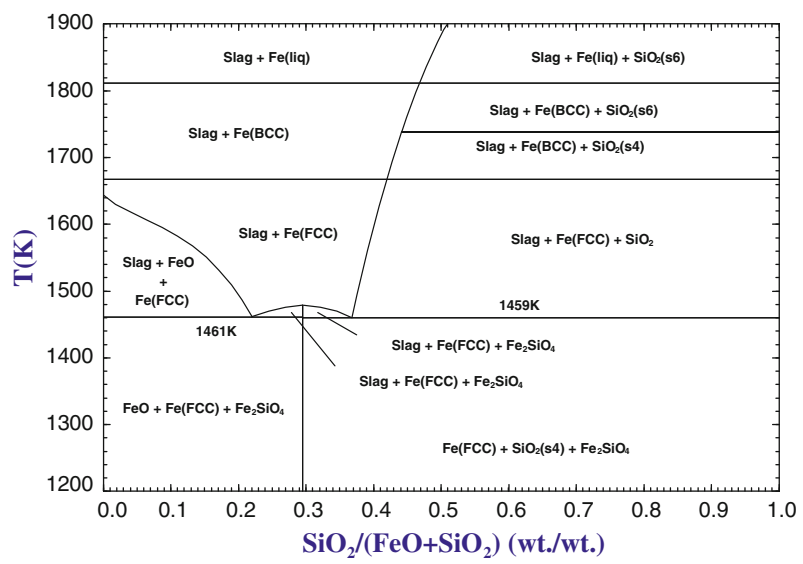

Fig. A2-Pseudo-binary phase diagram of the $\mathrm{FeO}-\mathrm{SiO}_{2}$ system (activity of Fe-FCC/-BCC/-liq. = 1) calculated by FactSage using the FToxid database. ${ }^{[16]}$

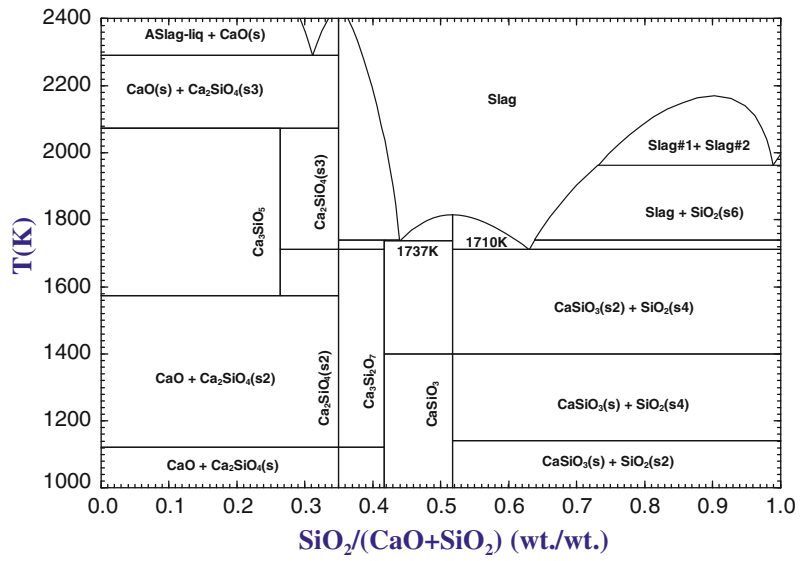

Fig. A3 - Pseudo-binary phase diagram of the $\mathrm{CaO}-\mathrm{SiO}_{2}$ system calculated by FactSage using the FToxid database. ${ }^{[16]}$ 


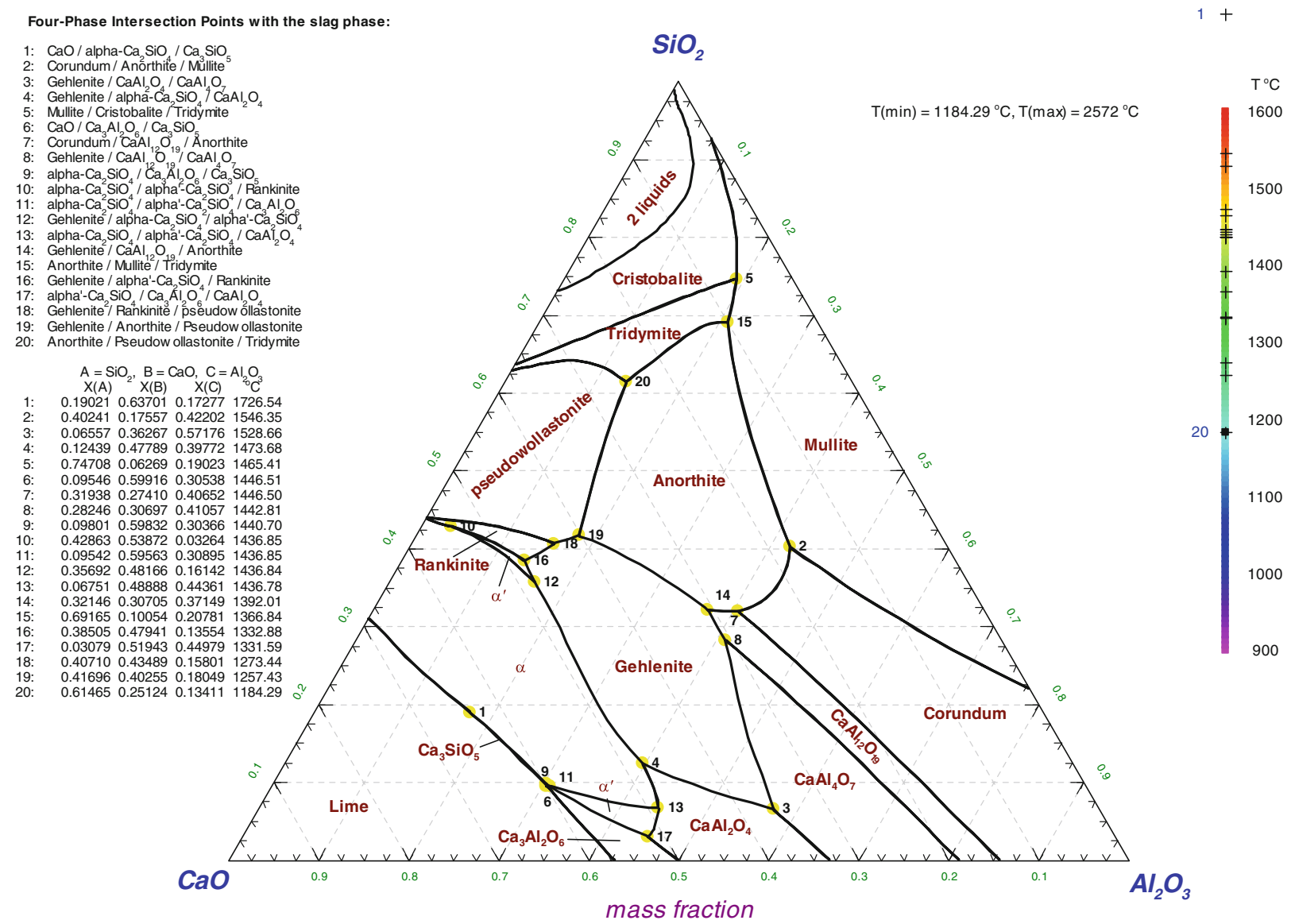

Fig. A4-Liquidus projection of the $\mathrm{SiO}_{2}-\mathrm{CaO}-\mathrm{Al}_{2} \mathrm{O}_{3}$ system calculated by FactSage using the FToxid database. ${ }^{[16]}$

\section{REFERENCES}

1. A. Ghosh and S.K. Majumdar: Int. J. Adv. Manuf. Technol., 2011, vol. 52, pp. 989-1003.

2. S. Ueda, S. Natsui, H. Nogami, J.-I. Yagi, and T. Ariyama: ISIJ Int., 2010, vol. 50, pp. 914-23.

3. X.F. Dong, A.B. Yu, S.J. Chew, and P. Zulli: Metall. Mater. Trans. B, 2010, vol. 41B, pp. 330-49.

4. H. Nogami, M. Chu, and J.-I. Yagi: Comput. Chem. Eng., 2005, vol. 29 , pp. $2438-48$.

5. C. Gao, L. Jian, and S. Luo: IEEE Trans. Ind. Electron., 2012, vol. 59, pp. 1134-45.

6. L. Jian and C. Gao: IEEE Trans. Ind. Electron., 2012, pp. 1-1.

7. F.A. Garcia, P. Campoy, J. Mochon, I. Ruiz-Bustinza, L.F. Verdeja, and R.M. Duarte: ISIJ Int., 2010, vol. 50, pp. 730-37.

8. X. Hao, F. Shen, G. Du, Y. Shen, and Z. Xie: Steel Res. Int., 2005, vol. 76, pp. 694-99.

9. D. Qiu, D.-J. Zhang, W. You, N.-N. Zhang, and H. Li: in International Conference on Apperceiving Computing and Intelligence Analysis, 2009 (ICACIA 2009), 2009, pp. 61-64.

10. H. Saxen and F. Pettersson: in IEEE Symposium on Computational Intelligence and Data Mining, 2007 (CIDM 2007), 2007, pp. 36875.

11. F. Pettersson, N. Chakraborti, and H. Saxen: Appl. Soft Comput., 2007, vol. 7, pp. 387-97.

12. F. Pettersson, H. Saxen, and K. Deb: Mater. Manuf. Process., 2009, vol. 24, pp. 343-49.

13. J.G. Peacey and W.G. Davenport: The Iron Blast Furnace, Theory and Practice, 1st ed., Pergamon Press, Oxford, 1979, pp. 1-251.

14. E. Jak and P. Hayes: High Temp. Mater. Process. (Lond.), 2012, vol. 31 , pp. 657-65.

15. V.I. Kulinich: Steel Transl., 2007, vol. 37, pp. 356-61.

16. C.W. Bale, E. Belisle, P. Chartrand, S.A. Decterov, G. Eriksson, K. Hack, I.H. Jung, Y.B. Kang, J. Melançon, A.D. Pelton, C. Robelin, and S. Petersen: CALPHAD, 2009, vol. 33, pp. 295-311.
17. G. Eriksson: Acta Chem. Scand., 1971, vol. 25, pp. 2651-58.

18. G. Eriksson: Chem. Scr., 1975, vol. 8, pp. 100-103.

19. S. Petersen, K. Hack, P. Monheim, and U. Pickartz: Int. J. Mater. Res., 2007, vol. 98, pp. 946-53.

20. W.T. Lankford, Jr.: The Making, Shaping, and Treating of Steel, $10^{\text {th }}$ ed., Association of Iron and Steel Engineers, Pittsburgh, PA, 1985, pp. 1-1572.

21. F.R. Feret: Analyst, 1998, vol. 123, pp. 595-600.

22. J.M. Jiménez Mateos, E. Romero, and C.G. de Salazar: Carbon, 1993, vol. 31, pp. 1159-78.

23. S. Dong, N. Paterson, S.G. Kazarian, D.R. Dugwell, and R. Kandiyoti: Energy Fuels, 2007, vol. 21, pp. 3446-54.

24. M. Lundgren, L. Sundqvist Ökvist, G. Hyllander, B. Jansson, and B. Björkman, in Scanmet IV: $4^{\text {th }}$ International Conference on Process Development in Iron and Steelmaking, Luleå, 2012, pp. $157-168$.

25. K.T. Jacob and S. Seetharaman: Metall. Mater. Trans. B, 1994 , vol. 25B, pp. 149-51.

26. S. Le Digabel: ACM Trans. Math. Softw., 2011, vol. 37, pp. 1-15.

27. A.R. Conn, K. Scheinberg, and L.N. Vicente: Introduction to Derivative-Free Optimization, Society for Industrial and Applied Mathematics, Philadelphia, PA, 2009, pp. 1-277.

28. V. Torczon: SIAM J. Optim., 1997, vol. 7, pp. 1-25.

29. M.D. McKay, R.J. Beckman, and W.J. Conover: Technometrics, 1979, vol. 21 , pp. 239-45.

30. C. Audet and J. Dennis: SIAM J. Optim., 2009, vol. 20, pp. 44572 .

31. F.H. Clarke: Optimization and Nonsmooth Analysis, Society for Industrial and Applied Mathematics, Philadelphia, PA, 1990, pp. $1-308$.

32. J.H. Strassburger: Blast Furnace - Theory and Practice, Gordon and Breach Science Publishers, New York, NY, 1969, vol. 1, pp. $1-1040$.

33. W. Dai, S. Seetharaman, and L.I. Staffansson: Metall. Trans. B, 1984, vol. 15B, pp. 319-27. 
34. G. Zuo: ISIJ Int., 2000, vol. 40, pp. 1195-1202.

35. A.K. Biswas: Principles of Blast Furnace Ironmaking, Cootha Publishing House, Brisbane, 1981, pp. 1-528.

36. P. Barnaba: Coke Mak. Int., 1993, vol. 5, pp. 47-54.

37. S.E. Offerman, L.J.G.W. van Wilderen, N.H. van Dijk, J. Sietsma, M.T. Rekveldt, and S. Van der Zwaag: Acta Mater., 2003, vol. 51, pp. 3927-38.

38. N. Tsuchiya, M. Tokuda, and M. Ohtani: Smelting of Low-Silicon Pig Iron in Blast Furnace, Kawasaki Steel Technical Report No. 6, 1982.

39. Q. Wang: Kuangwu Yanshi Diqiu Huaxue Tongbao, 1999, vol. 18, pp. $322-25$.

40. V.A. Dolinskii and A.A. Plyshevskii: Izv. Vyssh. Uchebn. Zaved. Chern. Metall., 1988, pp. 13-16.

41. J. Robertson: Mater. Sci. Eng. R Rep., 2002, vol. 37, pp. 129-281.

42. F. Spaepen: Phil. Mag., 1974, vol. 30, pp. 417-22.

43. E.P. Donovan, F. Spaepen, D. Turnbull, J.M. Poate, and D.C. Jacobson: J. Appl. Phys., 1985, vol. 57, pp. 1795-1804.
44. O.K. Belousov: Russ. Metall. (Metally), 2009, vol. 2009, pp. 48897.

45. A.I. Savvatimskiy: Carbon, 2005, vol. 43, pp. 1115-42.

46. A.T. Dinsdale: CALPHAD: Comput. Coupl. Phase Diagr. Thermochem., 1991, vol. 15, pp. 317-425.

47. G.I. Kerley and L. Chhabildas, Multicomponent-Multiphase Equation of State for Carbon, Sandia National Laboratories SAND2001-2619, 2001.

48. F.P. Bundy: J. Chem. Phys., 1963, vol. 38, pp. 631-43.

49. G. Pottlacher, R.S. Hixson, S. Melnitzky, E. Kaschnitz, M.A. Winkler, and H. Jäger: Thermochim. Acta, 1993, vol. 218, pp. 183 93.

50. E.P. Donovan, F. Spaepen, D. Turnbull, J.M. Poate, and D.C. Jacobson: Appl. Phys. Lett., 1983, vol. 42, pp. 698-700.

51. P.K. de Bokx, A.J.H.M. Kock, E. Boellaard, W. Klop, and J.W. Geus: J. Catal., 1985, vol. 96, pp. 454-67.

52. T.J. Konno and R. Sinclair: Acta Metall. Mater., 1995, vol. 43, pp. 471-84. 